\title{
NUCLEAR EMULSION SPECTROMETRY AT LOW AND INTERMEDIATE NEUTRON ENERGIES \\ (An Updating of HASL-162)
}

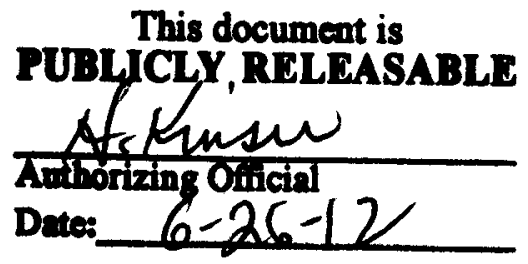

\author{
Robert S. Sanna \\ James E. McLaughlin \\ Keran O'Brien
}

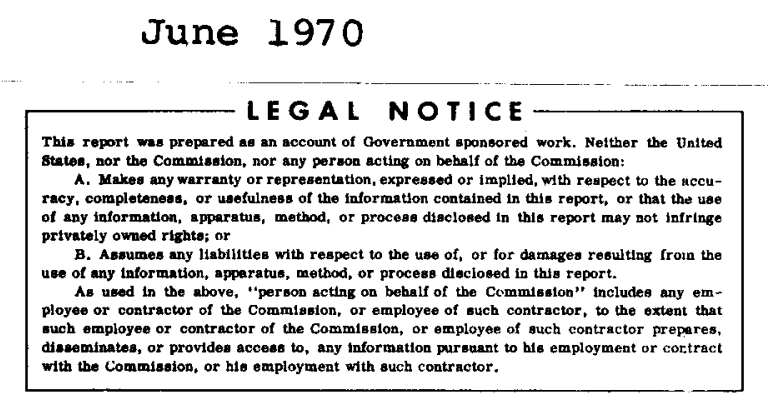

Health and Safety Laboratory

U. S. Atomic Energy Commission

New York, N. Y. 10014 


\section{DISCLAIMER}

This report was prepared as an account of work sponsored by an agency of the United States Government. Neither the United States Government nor any agency Thereof, nor any of their employees, makes any warranty, express or implied, or assumes any legal liability or responsibility for the accuracy, completeness, or usefulness of any information, apparatus, product, or process disclosed, or represents that its use would not infringe privately owned rights. Reference herein to any specific commercial product, process, or service by trade name, trademark, manufacturer, or otherwise does not necessarily constitute or imply its endorsement, recommendation, or favoring by the United States Government or any agency thereof. The views and opinions of authors expressed herein do not necessarily state or reflect those of the United States Government or any agency thereof. 


\section{DISCLAIMER}

Portions of this document may be illegible in electronic image products. Images are produced from the best available original document. 


\section{ABSTRACT}

Improvements and changes in our techniques for using nuclear track emulsions as neutron spectrometers are described. Emulsion development procedures, necessary data corrections, control of scanning errors, error propagation, and the analyses used to infer the neutron spectra are summarized. To test the spectrometric system, pseudo-proton track data were generated from a ${ }^{230} \mathrm{PuBe}$ spectrum by a Monte Carlo technique and used to produce a neutron spectrum for comparison with the original spectrum. Spectra from real measurements are presented. 
TABLE OF CONTENTS

$\underline{\text { Page }}$

TEXT

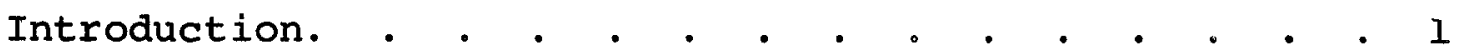

Processing Thick Emulsion Pellicles . . . . . . . 2

1. Changes in Processing Techniques. . . . . . 2

2. An Automatic Processing System . . . . . . 。3

Data Collection and Reduction . . . . . . . . . 4

1. Scanning the Emulsion . . . . . . . . . . 4

2. Escape Corrections . . . . . . . . . . . 5

3. Range Energy Relations . . . . . . . . . . 8

4. Gross Scanner Errors. . . . . . . . . . . 9

5. Packing of Track Coordinate Data. . . . . . . 12

Data Analysis and Error Propagation . . . . . . . 13

1. Program SARDINE

a. General Description. . . . . . . . . . 13

b. Edge-Normal Exposure . . . . . . . . . 13

c. Isotropic Exposure 。 。 . . . . . . 。 16

2. Program HERMES. • . . . . . . . . . 。 16

a. Spectral Unfolding . . . . . . . . . . 16

b. Error Propagation . . . . . . . . 18

Monte Carlo Generation of a Set of Standard Test Data,

Computer Program PROTEIN . . . . . . . . . . 19

I. General Description. . . . . . . . . . . 19

2. The Neutron Source . . . . . . . . . . . 19

3. Edge-Normal Exposure. . . . . . . . . . . 20

4. Isotropic Exposure . . . . . . . . . . . 22

Test Results. . . . . . . . . . . . . . . 25

1. Escape Correction Factors for Edge-Normal

Exposure. . • . • . • . • • . • • • . 25 
TABLE OF CONTENTS (Cont'd)

$\underline{\text { Page }}$

2. Microscope Accuracy . . . . . . . . . . . 27

3. Accuracy of Packing Routine . . . . . . . . 27

4. Neutron Spectrum from Edge Normal Data. . . . . 27

5. Neutron Spectrum from Isotropic Exposure . . . . 28

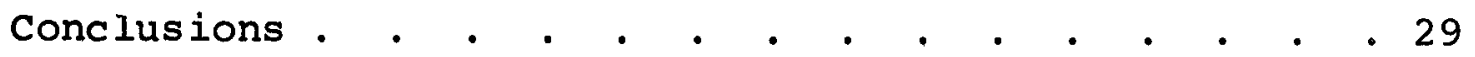

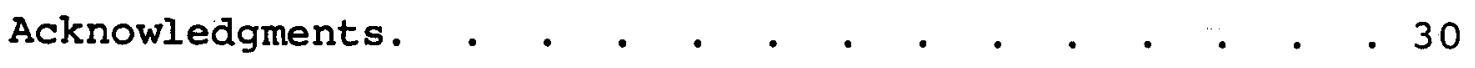

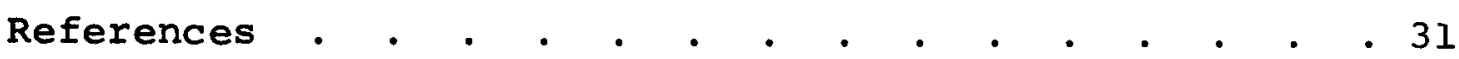

APPENDIX

Appendix 1. An Automatic Processing System . . . . 34

TABLES

Table 1. Processing Times for 600 Mircon Thick

Pellicles . . • . . . . . . • • . 36

Table 2. Emulsion Detection Efficiencies . . . . . 37

Table 3. Reaction Rate Per Centimeter of Emulsion

for Edge Normal Incident Monoenergetic

Neutrons. • • • • • • • • • • . . 38

Table 4. Coefficient for Range Energy Relation . . . 39

Table 5. Average Cosine $\theta$ for Pyramid of Half

Angles A and B. . . . . . . . . . . 40

Table 6. Protons Undergoing Non-Elastic Collisions. . 41

Table 7. Ratio of Monte Carlo Correction Factors to

Richards' Correction Factors for $20^{\circ}$

Acceptance Half Angle . . . . . . . . 42

Table 8. Specific Dose for $839 \mathrm{Pu}-\mathrm{Be}$ Neutrons. . . . 43 


\title{
TABLE OF CONTENTS (Cont'd)
}

\author{
ILLUSTRATIONS
}

Page

Figure 1. The differential np scattering cross

section in the forward direction . . . . 44

Figure 2. Edge normal escape correction factors for $\mathrm{Pu}-\mathrm{Be}$ neutrons and a $20^{\circ}$ acceptance half angle . . . . . . . . . . . . 45

Figure 3. Edge normal escape correction factors for $14 \mathrm{MeV}$ neutrons at a $40 \mathrm{~m}$ slant range and a $20^{\circ}$ acceptance half angle. . . . . . . 46

Figure 4. Edge normal escape correction factors for secondary neutrons from $2 \mathrm{GeV}$ protons on aluminum and a $20^{\circ}$ acceptance half angle. . 47

Figure 5. Face normal escape correction factors for $\mathrm{Pu}-\mathrm{Be}$ neutrons and a $20^{\circ}$ acceptance half angle . . . . . . . . . . . . . 48

Figure 6. Neutron spectrum from Monte Carlo generated coordinate data for edge normal exposure to $\mathrm{Pu}-\mathrm{Be}$ neutrons . . . . 49

Figure 7. HASL $10 \mathrm{Ci} 23{ }^{\circ} \mathrm{Pu}-\mathrm{Be}$ neutron source spectrum measured with nuclear emulsions, edge normal exposure . . . . . . . . 50

Figure 8. HASL measurement of D-T neutron spectrum at a slant range of $I I$ meters, edge normal exposure . . . . . . . . . 51

Figure 9. Neutron spectrum from Monte Carlo generated coordinate data for an isotropic exposure to $\mathrm{Pu}-\mathrm{Be}$ neutrons . . . . . 52

Figure 10. Comparison of nuclear track emulsion neutron spectral measurement made alongside the BNL Cosmotron with theory. . . . 53 


\section{INTRODUCTION}

Our first use of thick nuclear track emulsions as neutron spectrometers, was reported in $1964(1)$. We have since modified and improved both our experimental and analytical techniques. This report describes the methods now in use at our Laboratory:

Refinements in the processing of thick Ilford G-5 nuclear emulsions have been made to minimize distortion of the developed emulsion. The developing process has been extended to $\mathrm{K}-2$ and dilute emulsions.

More accurate shrinkage correction factors and proton range-energy relations are applied in analyzing the track measurements. A statistical comparison of the data from individual scanners is routinely performed to detect gross errors. In addition, as we usually accumulate data on about 10,000 proton tracks for each emulsion and these data are recorded one track per punched card, we have generated a large number of data cards. To facilitate data handling, a computer routine has been written which reduces the number of data cards to about one-ninth.

The recoil proton data collected from an emulsion are analyzed as either an edge-normal or isotropic exposure to yield a neutron spectrum. The statistical and propagated errors in the neutron spectrum are estimated.

To test our analytical procedures, sets of pseudoproton track coordinate data were generated by Monte carlo techniques for both edge-normal and isotropic exposures to a ${ }^{39} \mathrm{PuBe}$ neutron source having the spectrum reported by Anderson( $(2)$. These pseudo-proton coordinate data were analyzed to yield neutron spectra which were found to be comparable with the original spectrum. Measured spectra have also been compared with other appropriate measurements or theoretical results as a further test.

The specific doses in $\mathrm{rad} /\left(\mathrm{n} / \mathrm{cm}^{2}\right)$ are routinely computed from the emulsion data and compare well with published 
values. The specific doses are based on so-called first collision tissue dose conversions, and on maximum tissue dose conversions in a $30 \mathrm{~cm}$ thick tissue-like slab.

\section{PROCESSING THICK EMULSION PELLICLES}

\section{Changes in Processing Technigues}

As previously reported, we usp the isothermal developing process of Akagi and Lehman(1,3). The developing times for different nuclear emulsions, which are shown in Table I, vary significantly. For 600 micron thick emulsion pellicles, normal G-5 emulsions require 1.5 hours in the developer, while normal K-2 and G-5 emulsion diluted by four times the standard concentration of gelatin ( $4 \mathrm{X} \mathrm{Gel}$ ) require 4.5 hours and dilute (4X Gel) $\mathrm{K}-2$ requires 13.5 hours. As the Amidol in the developer oxidizes rapidly, the developer is replaced every 1.5 hours. The times for washing and fixing are not changed.

Errors in the measurement of the track coordinates can result from emulsion distortion due to shrinkage during drying. This shrinkage can reduce the pellicle thickness to one half or less. The removal of large amounts of undeveloped silver halide crystals from the gelatin matrix during the fixing of the developed pellicles produces voids which collapse during drying. To prevent or reduce shrinkage, these voids should be filled before or during drying with some optically clear material having nearly the same index of refraction as the emulsion.

Akagi and Lehman used a 35\% resin-in-alcohol bath after a $100 \%$ alcohol bath to fill the voids and reported that shrinkage is reduced nearly to zero(3). We were able to reduce the shrinkage only to 20 - 30\% with this technique. Similar results have also been obtained by adding $20 \%$ glycerin to the alcohol baths. The pellicles are air dried 
in the development racks rather than between the silk screens used with resin soaked emulsions. This allows the pellicles to contract freely and prevents distortion of the length and width. We chose the glycerin over the resin because:

a) Following the resin treatment, the emulsion pellicle becomes hard and brittle, and a very strong glue is required to mount it on a glass slide. If the slide is broken, the pellicle will also be shattered. With the glycerin solution, the pellicle is left pliable and can be easily mounted by squeegeeing it onto the slide. If the slide is broken, chances are that the pellicle will not be damaged.

b) Resin is not very soluble in alcohol and the preparation of the $35 \%$ resin-in-alcohol solution requires thorough mixing and filtering to remove remaining particles. Resin is very insoluble in water and the solution dries to a white gummy substance, making cleanup and handling difficult. The silk screens between which the emulsion pellicles are dried must be cleaned with generous amounts of $100 \%$ alcohol after each use. Glycerin, on the other hand, is soluble in both alcohol and water and, therefore, much easier to use.

c) The glycerin is added to the alcohol baths; resin requires an additional bath and the total processing time is extended by 24 hours.

Other concentrations of glycerine might decrease the shrinkage further but care must be taken, since the maximum working distance of our $100 x$ objective is only 630 microns and the pellicle thickness must not exceed this value. Micrometer measurements of unprocessed Ilford G-5 emulsion pellicles, nominally 600 microns thick, show that the actual thickness averages 660 microns with a few pellicles exceeding 700 microns. Therefore, a shrinkage of about $10 \%$ should be allowed for use of this emulsion with our objective.

\section{An Automatic Processing System}

Because of the long processing times for thick nuclear emulsions (33.5 hours for 600 micron G-5 emulsion pellicles), 
an automatic processing system was designed and fabricated by the HASL Instrumentation Division. The system requires attendance only at the beginning and end of the processing cycle. The $2 \frac{1}{6}$ gallon processing tank can hold up to 40 $2.5 \mathrm{~cm}$ by $7.5 \mathrm{~cm}$ emulsion plates or pellicles on four processing racks. All components of the system that come in contact with the processing chemicals are fabricated from plastic or type 316 stainless steel. A description of the system and its operation is given in Appendix I.

\section{DATA COLLECTION AND REDUCTION}

\section{Scanning the Emulsion}

Normally we collect recoil proton track sample sizes ranging from 4000 to as many as 20,000 tracks. The scanner measures the length and width of the emulsion with a ruler, and the thickness with the microscope fine focus. These measurements, along with the emulsion number and the scanner's identification number, are automatically recorded in the first 20 columns of each proton data card.

The scanner locates a proton track, aligns one end with the microscope crosshairs and presses the punch button on the control panel, causing the 20 columns of data control information and the $X, Y$, and $Z$ coordinates of the endpoint of the track to be punched on a data card. The operation is repeated for the other end of the track and the data card is then automatically ejected from the card punch. If the scanner finds that a track "escapes" the emulsion surface, is not straight, or is part of a star, he can reject the data card. These cards will be ignored during subsequent computer analyses. After measuring one track, the scanner locates the endpoint of the closest track and repeats the process. This "random walk", scanning technique results in a sample that closely approximates the population from which it was drawn(4). If a track is rejected for one of the 
above reasons the scanner returns to the endpoint of the last acceptable track and resumes his search. The procedure is repeated until a large enough sample is obtained.

\section{Escape Corrections}

There is a possibility that a recoil proton track will not be wholly contained within an emulsion of finite size. Because only those tracks that are wholly contained can be measured, a correction depending on the track length must be made to obtain a track sample with the correct relative number of short and long tracks.

As the emulsion length and width, $7.5 \mathrm{~cm}$ and $2.5 \mathrm{~cm}_{9}$ respectively, are very large compared to the track lengths usually measured, there are correspondingly few escapes in these directions. However, açcount must be taken of the thickness, because escape in this direction is usually significant.

Richards' derived expressions for track escape correction factors for a right, rectangular pyramid oriented along the direction of the incident neutrons $(B)$, namely

$$
\begin{aligned}
& C F=\frac{1}{w}=\frac{2 l \sin \alpha}{t} \text { for } \ell \sin \alpha \geq t, \\
& C F=\frac{1}{w}=\frac{2 t}{2 t-l \sin \alpha} \text { for } l \sin \alpha \leq t,
\end{aligned}
$$

where

$$
\begin{aligned}
w= & \text { track non-escape probability, } \\
\alpha= & \text { half-angle of the acceptance pyramid (these are } \\
& \text { defined as the maximum dip angle accepted in the } \\
& \text { analyses) } \\
t= & \text { emulsion thickness, and } \\
l= & \text { track length }(s) .
\end{aligned}
$$


Richards' correction formulae depend solely on the geometry of the emulsion and are based on the assumption that recoil proton tracks of a given length are isotropically distributed within the emulsion. This is true if the emulsion is exposed to an isotropic source of neutrons. Lehman and Wayland derived escape correction formulae for the random sampling technique we use $(\theta)$. This technique accepts tracks in any direction, i.e. the acceptance half angle is $90^{\circ}$. Their formulae are identical to Richards for $\alpha=90^{\circ}$.

For anisotropic exposures, the distribution of recoil protons of a given track length in the emulsion is not isotropic but depends upon the spectrum of the neutrons generating them. The escape correction factors, which depend upon the distribution of tracks of a given length in the emulsion, are also spectrum dependent. We have used our Monte Carlo program PROTEIN (described later) to calculate escape correction factors for various spectra of interest; these factors are more suitable than those obtained with Richards' formulae.

The escape correction factor is calculated from

$$
C F(E, \theta)=\frac{P_{\text {tot }}(E, \theta)}{P_{\text {end }}(E, \theta)},
$$

where

$$
\begin{aligned}
E= & \text { energy of recoil proton, } \\
\theta= & \text { maximum acceptable dip angle, } 20^{\circ} \text { in most } \\
\text { cases, } & \text { escape correction factor, } \\
C F(E, \theta)= & \text { total number of protons of energy } E \text {, within the } \\
& \text { dip angle } \theta, \text { that are generated in the emulsion, } \\
& \text { and } \\
P_{\text {tot }}(E, \theta)= & \text { number of protons of energy } E, \text { within the dip } \\
& \text { angle } \theta, \text { that end within the emulsion. }
\end{aligned}
$$


Accurate determinations of $C F(E, \theta)$ depend on accurate values of $P_{\text {tot }}(E, \theta)$ and $P_{\text {end }}(E, \theta)$; this means that large numbers of protons must be generated in the emulsion requiring even larger numbers of neutrons. This is illustrated by examining the efficiency values for the production of protons in G-5 emulsions. Table 2 summarizes such values for various monoenergetic neutrons as calculated using PROTEIN.

A great amount of computer time is needed and the approach is impractical for very "hard" spectra. However, one can force each neutron to generate a proton in the emulsion by substituting a reaction probability spectrum RPS(E) for the neutron spectrum $N(E)$ and setting the probability of interaction within the emulsion to one. This is valid, if the interaction probability is the same at every point in the emulsion.

We tested this assumption using a Monte Carlo technique to generate $n, p$ reactions along the 7.5 centimeter emulsion axis for monoenergetic neutrons between 0.1 and $25 \mathrm{MeV}$.

Above $0.7 \mathrm{MeV}$, the number of interactions per centimeter was constant for each energy within the statistics of the tests. At low energies there are relatively more interactions at the front edge than the back. Table 3 summarizes data for 0.1 and $0.7 \mathrm{MeV}$. We concluded that, for neutron energies of interest, the reaction rates are constant throughout the emulsion.

Neglecting neutron interactions with non-hydrogen nuclei, the reaction probability spectrum RPS $(E)$ is related to the neutron spectrum $N(E)$ and the $n-p$ cross section $\sigma(E)$ by,

$$
\operatorname{RPS}(E)=N(E) \cdot\left(1-e^{-\gamma \cdot \sigma(E) \cdot X}\right),
$$

where

$$
\begin{aligned}
& \mathrm{X}=\text { the amount of emulsion to be traversed }(7.5 \mathrm{~cm} \\
& \text { for an edge normal exposure), and } \\
& \gamma=\text { the hydrogen density in the emulsion. }
\end{aligned}
$$


Correction factors for some test cases are discussed later in the Results Section and compared with those obtained using Richards' formulae.

\section{Range Energy Relations}

The proton range is calculated from the measured track coordinates using

$$
R=\left[C_{X^{2}}\left(X_{1}-X_{2}\right)^{2}+C_{Y}^{2}\left(Y_{1}-Y_{a}\right)^{2}+C_{z}^{2}\left(Z_{1}-Z_{2}\right)^{2}\right]^{\frac{2}{2}},
$$

where

$$
\begin{aligned}
C= & \frac{t}{l} \text { for the } x, y, z \text { directions, } \\
t= & \text { emulsion dimension before development, } \\
l= & \text { emulsion dimension after development, } \\
\mathrm{X}_{1}, \mathrm{Y}_{1}, \mathrm{Z}_{2}= & \text { the coordinates of the first endpoint of the } \\
& \text { track, and }
\end{aligned}
$$

$\mathrm{X}_{2}, \mathrm{Y}_{\mathrm{Q}}, \mathrm{Z}_{2}=$ the coordinates of the second endpoint.

Though we routinely employ corrections for the three directions, the thickness correction $C_{z}$ is the most important.

In our previous report (1) we fit the range energy data below about $14 \mathrm{MeV}$ with equations of the form,

$$
E=a \sqrt{b R+c}-d,
$$

where

$$
\begin{aligned}
& E=\text { proton energy, } \\
& \mathrm{R}=\text { proton range, and } \\
& \mathrm{a}, \mathrm{b}, \mathrm{c}, \mathrm{d} \text { are constants. }
\end{aligned}
$$


Above $14 \mathrm{MeV}$ we used the formula,

$$
E=0.251 R^{0.581}
$$

derived by Bradner et al. $(\gamma)$ as reported by Bogaart and Vigneron( $($ ) . A more accurate fit of the range energy data is obtained with a set of equations of the same general form,

$$
\mathrm{E}=\mathrm{aR} \mathrm{b}^{\mathrm{b}}
$$

where

$$
\begin{aligned}
& E=\text { proton energy, } \\
& R=\text { proton range, and } \\
& a \text { and } b \text { are constants. }
\end{aligned}
$$

The values for $a$ and $b$ at various energies are shown in Table 4. Inversions of Equation (7) were used to calculate the proton ranges in our Monte Carlo calculations.

\section{Gross Scanner Errors}

Our experience indicates the need to assure that each scanners' data from the same emulsion is a representative sample and to detect any bias in the data collected even by experienced scanners. The adequacy of scanners' data is affected by the neutron fluence to which the emulsion is exposed, the neutron spectral shape, the associated charged particle and gamma-ray exposure, and the treatment and development of the emulsion. We try to overcome these problems by bracketing our exposures around an estimated "ideal" exposure of $10^{7} \mathrm{n} / \mathrm{cm}^{2}$, making duplicate exposures, using fresh emulsion whenever possible, and exercising great care with our developing procedures. Despite these. precautions, it is often necessary to retrieve data from emulsions which have a poor "signal-to-noise" ratio. 
A low "signal-to-noise" ratio makes it difficult for a scanner to distinguish short tracks (5-10 microns) from the background. The result may be a bias in favor of longer tracks or, conversely, a confusion of background grains and short tracks.

To guard against scanner bias, we test each new scanner with an emulsion exposed to known neutron spectra with good signal-to-noise ratios, e.g. the HASL $10-\mathrm{Ci}{ }^{2} 3^{\circ} \mathrm{Pu}-\mathrm{Be}$ source. The neutron spectrum is calculated from the proton data and compared with the known spectrum of the source.

For emulsion data from unknown spectra, the track data from several scanners are compared statistically to the aggregate or sum spectrum. As it is not convenient for each scanner to record exactly the same number of tracks, his raw spectrum $\mathrm{IP}_{i}(E)$ and the raw sum spectrum $I P_{T}(E)$ are normalized to 10,000 tracks. Because scanning for recoil protons below $0.7 \mathrm{MeV}$ was found to be unreliable, only the data above this energy are compared. The individual and aggregate or sum normalization factors are given by,

$$
N_{i}=10,000 / \sum_{E=0.7}^{E_{\max }} I P_{i}(E),
$$

where $E_{\max }$ is the energy limit above which no tracks are recorded. $\operatorname{IP}_{i}(E)$ is the number of events in the energy interval $\left(E-\frac{\Delta E}{2}, E+\frac{\Delta E}{2}\right)$. For the aggregate normalization, $\operatorname{IP}_{T}(E)$ is

$$
I P_{T}(E)=\sum_{i=I}^{N} I P_{i}(E),
$$

where $\mathrm{N}$ is the number of scanners.

Thus, the normalized spectra are given by 


$$
\begin{aligned}
& \operatorname{PN}_{i}(E)=N_{i} I P_{i}(E), \\
& \operatorname{PN}_{T}(E)=N_{T} I P_{T}(E) .
\end{aligned}
$$

Assuming our statistics to be Poissonian, the standard deviation for a scanner's normalized spectrum is

$$
\sigma_{i}(E)=N_{i} \sqrt{I P_{i}(E)}
$$

and for the normalized sum spectrum is

$$
\sigma_{T}(E)=N_{T} \sqrt{I P_{T}(E)}
$$

The number of standard deviations $\left[\mathrm{NSD}_{i}(E)\right]$ between an individual's data and the sum data is

$$
\operatorname{NSD}_{i}(E)=\frac{\mathrm{PN}_{i}(E)-P N_{T}(E)}{\sigma(E)},
$$

where the total deviation $\sigma(E)=\sqrt{\sigma_{T}^{2}(E)+\sigma_{i}^{2}(E)}$.

A scanner's data is accepted if his value of $\mathrm{PN}_{i}(E)$ falls within two standard deviations of the sum spectrum $P_{\mathrm{T}}(E)$. This comparison is valid for cases where the scanners have recorded nearly the same number of tracks above $0.7 \mathrm{MeV}$. For example, if one scanner has measured 5,000 tracks and two others have measured 1,250 each, then the normalization factor $N_{T}(E)$ will be weighted heavily by the first scanner, and the statistical comparison will not be a sensitive test of his data. At the higher energies, there may be few tracks in each energy bin and the recoil proton spectrum may be statistically poor in this region. A bin by bin comparison of the data under these circumstances is not reliable and consequently, we prefer to base our comparisons on the bins having the greatest number of tracks. 


\section{Packing of Track Coordinate Data}

Collecting about 10,000 cards for each emulsion soon leads to a handling and storage problem. A computer code was devised to reduce the number of data cards to about one-ninth.

Twelve pieces of data are recorded for each proton track, namely the emulsion and scanner identification numbers, a code to identify the last data card for an emulsion, the emulsion dimensions at the time of the measurement, and the track coordinates relating to an arbitrary origin.

To analyze the proton data, we need only the projected track lengths along each axis and the scanner identification. These are the data we retain in the packed form.

On our IBM-360/30 each integer variable used for data is represented by a full word, containing four bytes, each of which corresponds to a column on the standard 80 column data card. Data can also be expressed as a half word or two bytes. To retain four items of data, namely the three components of the track length and the scanner identification, we express these data in integer half word form and the data for a single track can be punched in eight columns of a data card. This enables us to store the data for nine tracks on a single card, leaving eight columns for the emulsion identification number and for numbering the packed data cards. The maximum value a half word integer can have is $2^{13}-1$ or $65,535$.

For a $2.5 \mathrm{~cm}$ by $7.5 \mathrm{~cm}$ emulsion, the longest a track component can be is $7.62 \mathrm{cms}$ or 762,000 microns. This number is larger than $2^{16}-1$ and cannot be expressed as a half word integer. However, the logarithm of the number, 13.5278, multiplied by $10^{3}$, can be used to preserve three place decimal accuracy. That is, the integer 13528 is less than $2^{18}-1$ and can be expressed as a half word.

Packing the data in this fashion not only reduces the number of data cards to be stored and handled by a factor of nine, but halves the computer time necessary to analyze a set of data. 
DATA ANALYSIS AND ERROR PROPAGATION

\section{Program SARDINE}

a. General Description - SARDINE, our computer program for the Spectral Analyses of Recoil Data in Nuclear Emulsions is used to form a recoil proton spectrum from each scanner's track coordinate data and compares them with the sum spectrum. SARDINE analyzes either original or packed data cards.

For an edge-normal exposure, a neutron spectrum is produced having the energy scale in either linear or logarithmic intervals. For an isotropic exposure, HERMES is used to unfold the neutron spectrum from the sum proton spectrum produced by SARDINE. In both cases, estimates of the error in the neutron flux as a function of the energy are made.

b. Edge-Normal Exposure - Edge-normal exposure are useful for measuring source spectra because the energy resolution is better than that for unfolded spectra. The direction of the incident neutrons must be known as in the case of a point, or well collimated source. The neutron energy is determined from the recoil proton energy using $E_{n} a^{2} \theta=E_{p}$, where $\theta$, the angle between the recoil proton and the incident neutron, is calculated from the coordinates of the recoil proton track. For slight departures from a point-source geometry, or when the incident neutron direction is less well known, one can use average angular values and $\sqrt{\cos ^{2} \theta}$ and proceed as follows

$$
R_{p} \overline{\operatorname{los} \theta}=R_{\mathbf{x}}
$$

where

$$
\begin{aligned}
R_{\mathrm{p}}= & \text { recoil proton range, } \\
\mathbf{R}_{\mathbf{x}}= & \text { projected recoil proton range along the direction } \\
& \text { of the incident neutron, and } \\
\overline{\operatorname{Cos}}= & \text { average cosine for an acceptance pyramid with } \\
& \text { half angles } A \text { and } B ; \text { an }=\mathrm{N} / 4 \text { (Tan } A \text { ) (Tan } B \text { ). }
\end{aligned}
$$$$
-13-
$$ 
We use $A=B=20^{\circ}$. The value for $N$ was obtained from an expression by Allred and Armstrong( $\theta$ ). Table 5 lists values of $\sqrt{6} \theta$ for various angles $A$ and $B ;$ the values for $10^{\circ}$ and $20^{\circ}$ agree well with the corresponding two values computed earlier by Allred and Armstrong(').

The recoil proton energy $E_{p}$ is obtained from $R_{p}$ using the range-energy relationships, and the neutron energy $E_{n}$ from

$$
E_{n} \overline{\cos ^{2} \theta}=E_{p}
$$

Each track is then placed in the appropriate energy bin and the neutron spectrum is obtained from

$$
N\left(E_{n}\right)=\frac{P\left(E_{n}\right) \cdot C F\left(E_{p}\right)}{\gamma \sigma_{n-p}\left(E_{n}, E_{p}\right)}
$$

where

$$
\begin{aligned}
N\left(E_{n}\right)= & \text { neutron spectrum, } \\
P\left(E_{n}\right)= & \begin{array}{l}
\text { number of recoil protons per unit energy } \\
\text { measured in the emulsion, }
\end{array} \\
C F\left(E_{p}\right)= & \text { correction factor for protons that escape } \\
& \text { the emulsion, and } \\
\sigma_{n-p}\left(E_{n}, E_{p}\right)= & \text { the differential energy cross section for } \\
& n-p \text { scattering in the forward direction. }
\end{aligned}
$$

Although the recoil proton tracks are grouped according to $E_{n}=E_{p} / \cos ^{2} \theta$, the escape correction factors are a function of track length and therefore $E_{p}$.

Since we select only those proton tracks in a 10 or $20^{\circ}$ acceptance half angle, we use the $n-p$ scattering cross 
section for the forward direction. We have fit the experimental cross-section data reported in BNL-400 using Gammel's formulation below $65 \mathrm{MeV}$, a corrected version of Gammel's formulation between 65 and $300 \mathrm{MeV}$ and a polynomial fit above $300 \mathrm{MeV}(10.11)$. Above $550 \mathrm{MeV}$, the cross sections are as sumed to be constant. Figure $I$ is a comparison of our fit and the available data.

When measuring very energetic spectra, i.e. $E_{\max }>25$ $\mathrm{MeV}$, two further corrections to the recoil proton data should be considered. The first is a correction for recoil protons that undergo non-elastic collisions with non-hydrogen nuclei in the emulsion. The percentage of such collisions is given by

$$
\operatorname{PER}\left(E_{p}\right)=100\left[1-\left(\operatorname{EXP} \int_{0}^{E_{p}} \frac{\sigma\left(E_{p}\right)}{S\left(E_{p}\right)} d E_{p}\right)^{-1}\right]
$$

where

$$
\begin{aligned}
S\left(E_{p}\right)= & \text { the stopping power interpolated from tables } \\
& \text { in Reference } 12 \text {, and } \\
\sigma\left(E_{p}\right)= & \text { the non-elastic cross section for protons from } \\
& \text { Reference } 13 .
\end{aligned}
$$

For convenience, we use a polynomial fit of $\operatorname{PER}\left(E_{p}\right)$. Values from the fit are compared in Table 6 with those from Equation (16). The correction factor $\mathrm{CP}\left(\mathrm{E}_{\mathrm{p}}\right)$ is related to $\operatorname{PER}\left(\mathrm{E}_{\mathrm{p}}\right)$ by

$$
C P\left(E_{p}\right)=\frac{100}{100-\operatorname{PER}\left(E_{p}\right)}
$$

As can be seen from Table 6 this correction increases to only $1 \%$ at $25 \mathrm{MeV}$ and becomes significant only above about $50 \mathrm{MeV}$.

The second correction accounts for proton generation from neutron interactions with the non-hydrogen nuclei of the emulsion. Using the cross section data of Reference 13, a 
proton spectrum corresponding to the neutron spectrum calculated from Equation (15) and corrected by Equation (17) is calculated and compared to the measured distribution. The neutron and proton spectra are then recomputed iteratively until convergence is obtained.

We recently attempted to measure neutron yields as a function of energy and angle from targets bombarded with multi-GeV protons. It was for this experiment that these two corrections were derived.

Overall errors in the resultant neutron spectrum are estimated assuming Poisson statistics and the approximation,

upper limit $=N(E) \cdot[P(E)+0.9+\sqrt{P(E)+0.9}] / P(E)$, and

lower limit $=N(E) \cdot[P(E)+0.01-\sqrt{P(E)-0.31}] / P(E)$,

for $68 \%$ confidence limits.

For each neutron spectrum, the specific doses in rads/ $\left(\mathrm{n} / \mathrm{cm}^{2}\right)$ are computed from the first collision dose data of Davis(14) and N.B.S. Handbook $75(18)$ and from the maximum specific dose data of Irving et al. (26). Auxier et al.(17) and Ritts et al.(18) have shown that the total tissue KERMA factors for 4- and 1l-element tissue approximate those for the first collision dose fairly well in the emulsion energy range.

c. Isotropic Exposure - For an isotropic exposure a recoil proton spectrum is formed from tracks measured over all angles. Each track is corrected for its escape probability using Richards' correction factors( 8 ). The recoil proton spectrum is then used as input to HERMES, our iterative unfolding program.

\section{Program HERMES}

a. Spectral Unfolding - For an isotropic exposure the neutron spectrum is related to the recoil proton spectrum by 
the integral equation

$$
P\left(E_{p}\right)=\int_{0}^{\infty} \gamma \sigma_{n, p}\left(E_{n}, E_{p}\right) N\left(E_{n}\right) d E_{n}
$$

where

$$
\begin{aligned}
P\left(E_{p}\right)= & \text { the recoil proton spectrum, corrected for } \\
& \text { escape, per } \mathrm{cm}^{3} \text { of emulsion per MeV, } \\
\gamma= & \text { the hydrogen atom density of emulsion, } \\
\sigma_{\mathrm{n}, \mathrm{p}}\left(E_{\mathrm{n}}, E_{\mathrm{p}}\right)= & \text { the differential energy cross section for } \mathrm{n}-\mathrm{p} \\
& \text { scattering, and } \\
\mathrm{N}\left(E_{\mathrm{n}}\right)= & \text { the neutron spectrum per } \mathrm{cm}^{2} \text { per MeV. }
\end{aligned}
$$

The above equation is approximated by the matrix product

$$
P=\Sigma_{N},
$$

which is solved for $\mathrm{N}$ using the iterative technique of Scofield and Gold(19). After each iteration for $N,{ }_{N}(\mu)$, where $\mu$ is the number of the iteration, is smoothed by Simpson's rule,

$$
N_{i}^{(\mu)}=(1 / 6)\left(N_{i-1}(\mu)+4 N_{i}^{(\mu)}+N_{i+1}(\mu)\right) .
$$

This permits one to deal with nonoscillatory solutions to the matrix equation.

Experience has shown that convergence is usually achieved within 500 iterations. We, therefore, routinely perform 500 iterations and calculate $P(500)$ from $N(500)$ for comparison with the input spectrum $P\left(E_{p}\right)$. A "distance" is calculated from 


$$
D=\sum_{E_{p} \min }^{E_{p \max }} \sqrt{\left(P\left(E_{p}\right)-P^{(500))^{2}}\right.}
$$

and used as a measure of convergence. If the value of the distance $D$ is less than $2 \%$ of the sum of the recoil proton spectrum $P(E)$ the convergence is considered acceptable.

HERMES produces a neutron spectrum with 60 logarithmic energy bins between the minimum and maximum energies of the recoil proton spectrum which has up to 200 linear energy bins. First collision and maximum specific doses are obtained for the neutron spectrum in the manner previously indicated.

b. Error Propagation - Following the propagation of errors through the iterative and smoothing routines used to infer the neutron spectrum is extremely difficult and impractical. We use a procedure to estimate the effect of experimental errors on the determination of the neutron spectrum from the recoil proton energy distribution, which is based on work by Evans $(20)$.

The procedure consists in perturbing each channel of the original proton spectrum in a random manner, based on the assumption that the statistical error of each channel has a normal distribution about the measured value. The perturbed data are then unfolded, along with the measured spectrum and four neutron spectra are obtained. The range between the four values obtained at each energy point can be taken to be an estimate of the standard error. Assuming $\overline{\mathrm{x}}=$ mean or measured value, $\sigma=$ standard deviation, and $\mathbf{x}=$ perturbed value, then $\mathrm{p}(\mathrm{x})$ is the relative frequency with which observations will fall below a specified value $\mathbf{x}$ and is the area under the distribution curve from - $-\infty$ to the specified value

$$
p(x)=\frac{1}{\sqrt{2 \pi}} \int_{-\infty}^{x} \frac{e^{-\frac{1}{\varepsilon}\left(\frac{x-\bar{x}}{\sigma}\right)^{2}}}{\sigma} d x ; 0<\dot{p}(x) \leq 1
$$


In our procedure, $p(x)$ is randomly generated, and Equation (23) is approximated by a formula due to Hastings(21) which allows the solution of the integral equation for $x$.

\section{MONTE CARLO GENERATION OF A SET OF STANDARD TEST DATA, COMPUTER PROGRAM PROTEIN}

\section{General Description}

Our computer programs SARDINE and HERMES were tested using data having no scanner or other experimental errors. Using a Monte Carlo technique, pseudo-recoil-proton tracks in the standard emulsion were generated for both edge-normal and isotropic exposures to a known neutron spectrum. The coordinates of the recoil proton tracks were recorded on data cards and resemble closely the data from a real emulsion analysis.

The data were unfolded and the neutron spectrum compared to the original test spectrum. Since shrinkage varies from emulsion to emulsion and the correction is simple, it was ignored in these tests and the eimulsion was assumed to have the same dimensions after development as during exposure, namely $7.5 \mathrm{~cm}$ by $2.5 \mathrm{~cm}$ by 600 microns thick, and a hydrogen density of $3.645 \times 10^{22}$ atom $/ \mathrm{cm}^{3}$. These values are nominal for the Ilford G-5 emulsions with extra plasticiser, that we routinely use.

In the Monte Carlo techniques we use a pseudo random variable that has an equal probability of having any value between zero and one. Routines for assigning values to such a variable are available for most computers. In the following sections we designate this random number by the letter $Q$.

\section{The Neutron Source}

First, a mathematical model of the selected neutron spectrum is formed and neutrons are generated at random 
energies. Our test spectrum was that for a $230 \mathrm{Pu}-\mathrm{Be}$ source measured by Anderson( $(z)$.

The probability that a neutron will have an energy $E_{n}$ is given by

$$
P=\frac{\int_{E_{\min }}^{E_{n}} N(E) d e}{\int_{E_{\min }}^{E_{\max }} N(E) d e},
$$

where

$$
\begin{aligned}
& N(E)=\text { the neutron spectrum, } \\
& E_{\min }=\text { the minimum energy of the neutron spectrum, and } \\
& E_{\max }=\text { the maximum energy of the neutron spectrum. }
\end{aligned}
$$

The random number generator enables us to select a value for $P=Q$, between zero and one. The integral equation can then be solved for $E_{n}$ numerically.

\section{Edge-Normal Exposure}

A coordinate system is set up with its origin at one corner of the emulsion and the $x$ axis parallel to its length $(7.5 \mathrm{~cm})$, the $Y$ axis parallel to its width $(2.5 \mathrm{~cm})$, and the $Z$ axis parallel to its thickness (600 microns). For an edge-normal exposure the neutrons are incident on the $Y, Z$ plane and are parallel to the $x$ axis. The neutron enters the emulsion at any point on the $Y$, $Z$ surface so that the coordinates of its entry point, in units of microns, are 0 , $25,000 Q, 600 Q$.

The probability $\mathrm{P}$ that a neutron will interact within a distance $\mathrm{D}$ is given by

$$
P=1-e^{-\gamma_{\sigma} D},
$$


where

$$
\begin{aligned}
& \gamma=\text { hydrogen density of the emulsion, and } \\
& \sigma=\begin{array}{l}
\text { differential energy scattering cross section for } \\
\text { hydrogen. }
\end{array}
\end{aligned}
$$

The integral equation of the random number $Q$ is

$$
Q=\frac{\int_{0}^{D} 1-e^{-\gamma \sigma} d}{\int_{0}^{\infty} 1-e^{-\gamma \sigma} d}
$$

which yields $D=-\ln Q / \gamma \sigma$.

If $\mathrm{D} \leq 75,000$ microns, an interaction has occurred at a point in the emulsion with the coordinates $\mathrm{Px}_{1}=D$, $P Y_{1}=Y, P z_{1}=Z$.

For neutron energies less than about $15 \mathrm{MeV}$, the protons are generated isotropically in the center of mass system and the energy of the proton is obtained from

$$
E_{p}=Q E_{n}
$$

The range $R_{p}$ of a proton of energy $E_{p}$ is obtained from the range-energy relationships previously discussed. $\theta$ can be obtained from $\theta=\operatorname{arcm}\left(\sqrt{E_{p} / E_{n}}\right)$. This is the angle the proton makes with the direction of the incident neutron (which is parallel to the $X$ axis) and is given by $R_{X}=R_{p} \cos$.

The angle the track makes in the $\mathrm{Y}-\mathrm{Z}$ plane has a constant probability between 0 and $2 \pi$, so that the angle called $\varphi$ equals $2 \pi Q$. Then the projections on the $Y$ and $Z$ axes are given by 


$$
\begin{aligned}
& R_{Y}=\sqrt{R_{p}^{2}-R_{X}^{2}} \sin \varphi \text {, and } \\
& R_{Z}=\sqrt{R_{p}^{2}-R_{X}^{2}} \operatorname{los} \varphi
\end{aligned}
$$

and the coordinates of the endpoint of the proton track are

$$
\begin{aligned}
& P_{X_{2}}=P_{X_{1}}+R_{X^{\prime}} \\
& P_{Y_{2}}=P_{Y_{1}}+R_{Y}, \\
& P_{Z_{2}}=P_{Z_{1}}+R_{Z} .
\end{aligned}
$$

If

$$
\begin{aligned}
& 0<\mathrm{P}_{\mathrm{X}_{a}} \leq 75,000, \\
& 0<\mathrm{P}_{\mathrm{Y}_{a}} \leq 25,000 \\
& 0<\mathrm{P}_{\mathrm{Z}_{a}} \leq 600
\end{aligned}
$$

the track is completely contained within the emulsion and its coordinates are punched. Another neutron is selected and the process repeated.

If the neutron does not interact within the emulsion or if the recoil proton escapes through one of the emulsion surfaces no coordinates are punched and a new neutron is selected. This procedure is repeated until the desired number of valid recoil proton tracks have been generated.

\section{Isotropic Exposure}

The geometric considerations for an isotropic exposure are more complex than for an edge normal exposure. The neutron can enter through any of six surfaces of the $7.5 \mathrm{~cm}$ by $2.5 \mathrm{~cm}$ by $600 \mu \mathrm{m}$ emulsion. The probability of it entering through any surface is proportional to the area of that surface. 
A track making an angle $\varphi$ with an emulsion surface sees a projection of that surface having an area $\mathrm{X}=\mathrm{A}$ are where can cave any value between zero and one with equal probability. The random number generator selects the $=Q$. This method of selecting the surface through which the neutron enters and the angle it makes with the incident neutron direction is a valid representation of an isotropic exposure.

A coordinate system is chosen so that the origin is at one corner of the emulsion and the $z$ axis is perpendicular to the surface of entry. Then the coordinates of the entry point of the neutron are given by

$$
\begin{aligned}
& P_{X}=Q L_{X}, \\
& P_{Y}=Q L_{Y}, \text { and } \\
& P_{Z}=0 \text { if is positive or } \\
& P_{Z}=L_{Z} \text { if is negative, }
\end{aligned}
$$

where $L_{X}$, and $L_{Y}$ and $L_{Z}$ are the emulsion dimensions along the $X, Y$, and $Z$ axis respectively.

The neutron will travel a distance $D$ before interacting with a hydrogen atom to give us a recoil proton, where

$$
D=-\ln Q / \gamma \sigma,
$$

where

$$
\begin{aligned}
& \gamma=\text { hydrogen atoms } / \mathrm{cm}^{3}, \text { and } \\
& \sigma=\text { np scattering cross section. }
\end{aligned}
$$

The $\mathbf{z}$ projection of this distance is 


$$
D_{\mathbf{z}}=\mathrm{D} \operatorname{cose} \text {. }
$$

The neutron also forms an angle $w$ in the $X-Y$ plane with the $Y$ axis so that $\omega=Q 2 \pi$, and the $X$ and $Y$ projections of the distance travelled are given by

$$
\begin{aligned}
& D_{X}=\sqrt{D^{2}-D_{Z}^{2}} \text { sinw } \\
& D_{Y}=\sqrt{D^{2}-D_{Z}^{2}}
\end{aligned}
$$

The coordinates of the point of interaction, then, are $I_{x}=P_{x}+D_{x}, I_{y}=P_{y}+D_{y}$, and $I_{z}=P_{z}+D_{z}$. If $0 \leq I_{X} \leq L_{X}, 0 \leq I_{Y} \leq L_{y}$, and $0 \leq I_{z} \leq L_{z}$, then the neutron has generated a recoil proton within the emulsion and we can continue. If the interaction does not occur in the emulsion we choose another neutron and start over.

If the neutron interacts within the emulsion, the axis system is translated and rotated so that the origin is at the point of interaction and the $\mathrm{z}^{\prime}$ axis parallel to the direction of the neutron. The relationship between the old and new coordinate systems is given by

$$
\begin{aligned}
& \mathbf{P X}=\mathbf{I}_{\mathbf{X}}+\mathbf{P X}^{\prime} \varphi \omega+\mathbf{P Z}^{\prime} \sin \varphi \omega+\mathbf{P Y}^{\prime} \sin \omega \\
& \mathbf{P Y}=\mathbf{I}_{\mathbf{Y}}+\mathbf{P Y ^ { \prime }} \omega-\mathbf{P X}^{\prime} \varphi \sin \omega-\mathbf{P Z}^{\prime} \sin \varphi \sin \omega, \\
& \mathbf{P Z}=\mathrm{I}_{\mathbf{Z}}+\mathbf{P Z ^ { \prime }} \varphi-\mathbf{P X}^{\prime} \sin \varphi .
\end{aligned}
$$

These expressions are useful to convert the coordinates of the end point of the recoil proton track EX', EY' and EZ' in the new system to the original system. The recoil proton energy is obtained from the neutron energy using $E_{p}=Q E_{n}$ and $\theta=\arccos \sqrt{E_{p} / E_{n}}$. The range is obtained from the range energy relationships and the end point coordinates are 


$$
\begin{aligned}
& E Z^{\prime}=R \cos \theta, \\
& E X^{\prime}=\sqrt{R^{d}-E Z^{\prime \sigma}} \sin \varphi \text {, and } \\
& E Y^{\prime}=\sqrt{R^{2}-E Z^{\prime 3}} \operatorname{cosec},
\end{aligned}
$$

where $\varphi=2 \pi Q$. Transforming $\mathbf{E X}^{\prime}, \mathbf{E Y}^{\prime}$ and $\mathbf{E Z} \mathbf{Z}^{\prime}$ to the original coordinate system we obtain the coordinates, EX, EY, EZ of the end point of the recoil proton track. Then if $0 \leq E_{X} \leq L_{X}$, $0 \leq E_{Y} \leq L_{Y}$, and $0 \leq E_{z} \leq L_{z}$ as before, the track is contained completely in the emulsion and its coordinates IX, IY, IZ and EX, EY and EZ are punched; otherwise it is rejected. A new neutron is selected and the process repeated until the desired number of tracks have been punched. Each tack is randomly assigned to one of seven pseudo-scanners.

\section{TEST RESULTS}

\section{Escape Correction Factors for Edge-Normal Exposures}

Using the Monte Carlo technique, we calculated the escape correction factors for edge-normal exposures to three source spectra, $239 \mathrm{Pu}-\mathrm{Be}, 14 \mathrm{MeV}$ monoenergetic, and the secondary neutron spectrum per steradian resulting from the bombardment of an aluminum target by $2 \mathrm{GeV}$ protons. For the $239 \mathrm{Pu}-\mathrm{Be}$ spectrum we used the data of Anderson( 2 ), for the $14 \mathrm{MeV}$ spectrum we used the spectrum calculated by straker for a: range of 40.08 meters from a D-T generator( $a \mathrm{a}$ ), and for the secondary neutron spectrum we used the calculated spectrum of Alsmiller (11). Reaction probability spectra were derived and PROTEIN was adapted so that each neutron interacted somewhere in the emulsion. Large samples of the proton spectrum were taken and the correction factors for a $20^{\circ}$ acceptance cone calculated. Our results are compared with those obtained using Richards' formulation in Figures 2, 3 and 4 .

It can be seen from Figures 2 and 3 that the Monte Carlo escape correction factors agree with Richards reasonably well 
to about $90 \%$ of the maximum neutron energy of the spectrum; here the values decrease to one at the maximum energy. Since $E_{p}=E_{n} \cos ^{2} \theta$, when $E_{p}$ approaches $E_{n}$, then $\cos ^{2} \theta$ approaches $I$ and $\theta$ approaches $0^{\circ}$, the proton whose energy approximates that of the maximum neutron energy will proceed in the direction of the neutron. For an edge normal exposure this direction is along the length of the emulsion, which can be considered infinite at these energies, $10-15 \mathrm{MeV}$, and no escape would occur.

For harder spectra, the Monte Carlo results in Figure 4 are substantially below Richards between 20 and $60 \mathrm{MeV}$, but return to Richards' values between 65 and $100 \mathrm{MeV}$, the maximum proton energy considered. At these energies the proton range is large (a few $\mathrm{cm}$ ) and the length of the emulsion can no longer be considered infinite, but will contribute substantially to the proton escape probability.

Table 7 shows the ratios of the Monte Carlo calculated correction factors to the results obtained using Richards' formulae. For the two low energy $(<15 \mathrm{MeV})$ spectra the difference is less than $5 \%$ except near the maximum energy of the spectra where the difference approaches $20 \%$. We have, therefore, concluded that any error in using Richards' formulae is within our measurement errors for these type of spectra. However, for the secondary neutron spectrum from $2 \mathrm{GeV}$ protons on aluminum the difference is as large as 30 $45 \%$ in the energy range $20-60 \mathrm{MeV}$ and cannot be ignored. Therefore, for spectra with energies greater than $15-20 \mathrm{MeV}$, we rely on our Monte Carlo program to calculate track escape correction factors.

We have exposed emulsions, isotropically, edge normally and face normally to a ${ }^{239}$ PuBe source. We used Richards' formulae for the isotropic and edge-normal escape correction factors and Monte Carlo results for the face-normal exposure of a 600 micron emulsion. Figure 5 is a comparison of these results with Richargs' formulae. As the escape correction factors get very large, above about $6 \mathrm{MeV}$, we do not expect to obtain a good spectrum from the face-normal data. 


\section{Microscope Accuracy}

To test the ability of our computer programs to properly analyze the coordinate data obtained from our microscope measurements, our Monte carlo program PROTEIN was used to generate test coordinate data. Using the ${ }^{239} \mathrm{Pu}-\mathrm{Be}$ spectrum reported by Anderson from stilbene measurement as our neutron source model, 20,000 sets of coordinate data were generated for both an edge-normal and an isotropic exposure.

Recoil proton spectra were obtained for $0.1 \mathrm{MeV}$ intervals and $90^{\circ}$ acceptance half angles from the coordinate data and directly from the recoil proton energies calculated by PROTEIN. A comparison of the spectra shows that about $1.75 \%$ or 350 tracks have been shifted from one bin to another. These shifts occur randomly and are due to truncation of the coordinate data to plus or minus one micron, a value which corresponds to the accuracy of our microscope stage. Increasing the accuracy of the readout to 0.1 microns and repeating the calculation reduces to $0.35 \%$ the number of tracks that are shifted to another bin.

\section{Accuracy of Packing Routine}

To test PACK, the coordinate data from the Monte carlo calculations were packed and then analyzed to yield proton spectra $\left(\Delta E=0.1 \mathrm{MeV}\right.$, acceptance half angle $\left.=90^{\circ}\right)$. The spectrum obtained was compared with the one obtained directly from the coordinate data and the number of tracks shifted was about 65 or $0.33 \%$. which is small when compared to other errors (e.g., $1.75 \%$ for the \pm one micron accuracy of the microscope).

\section{Neutron Spectrum from Edge Normal Data}

The 20,000 coordinate cards generated by PROTEIN were packed and these data analyzed using the exact cosines version of SARDINE and a $20^{\circ}$ acceptance half angle. The neutron spectrum obtained is shown in Figure 6 along with the input spectrum. The agreement is good and differences can be attributed to errors due to the measurement accuracy of plus or minus one micron. Figure 7 shows the results of an actual measurement of the spectrum of the HASL $10 \mathrm{Ci}{ }^{23} \mathrm{Pu}-\mathrm{Be}$ 
neutron source. The agreement with Anderson's measurement is good and the only peak we do not resolve is the one at $9.75 \mathrm{MeV}$ where the statistics of our measurements are very poor. Table 8 lists the values for first collision and maximum specific dose obtained from the spectra. The agreement is good.

Figure 8 shows the results obtained from the measurement of the neutron spectrum at a slant range of 11 meters from the D-T neutron source during Operation HENRE. Also shown is the spectrum calculated by straker for a slant range of 40.08 meters. While close agreement is not expected because of the difference in slant range it can be seen that the spectra have the same general shape. The statistics of our measurement, particularly between 4 and $12 \mathrm{MeV}$ are not good and there is some point scatter. However, we do resolve the major peak of the D-T spectrum between 14 and $15 \mathrm{MeV}$.

\section{Neutron Spectrum from Isotropic Exposure}

The coordinate cards generated by PROTEIN for an isotropic exposure were analyzed by SARDINE and HERMES. Figure 9 compares the envelope of the resulting neutron spectrum with Anderson's measurement (a). Agreement below $4.0 \mathrm{MeV}$ is good but, above that energy, our method of analysis cannot resolve the peaks and we get a smooth curve through them. This is due, we feel, to the smoothing performed upon the neutron spectrum after each iteration in our unfolding program HERMES. The integral quantities, i.e., specific dose, are not seriously affected by this smoothing and agreement with other values is good, as can be seen from Table 8 .

Figure 10 compares the results obtained by HERMES from a measurement alongside the BNL cosmotron with the theoretical results of 0 'Brien(24). The agreement is very good, and the smoothing performed on the spectrum is, in fact, helpful as the spectrum being measured is smooth. 


\section{CONCLUSIONS}

The edge-normal method of analyses gives good results for discrete source spectra with a maximum energy below 15 MeV. The experimental conditions must be controllable and the direction of the neutrons well known. The limit of the microscope stage accuracy, within one micron, limits the accuracy of the results obtained. However, when measuring spectra where it is desirable to separate peaks, this is the best means of doing it with nuclear emulsions.

The use of HERMES to unfold spectra from isotropicallyexposed emulsions produces lower resolution spectra than those obtained from an edge-normal exposure. Where spectra are expected to be smooth, as for leakage spectra through accelerator shields, good agreement with theory is obtained.

The specific dose values for either method of analyses agree with one another and with actual values fairly well. For dosimetric purposes either method of analysis gives adequate results.

The use of Richards' escape correction factor for isotropic data is valid and the error in using it for edge normal cases below $15 \mathrm{MeV}$ is not sufficient to warrant a Monte Carlo calculation of correction factors for each class of spectra. However, for harder spectra the error can become significant and must be considered when analyzing the data.

The use of PACK to condense the number of data cards to be handled and stored, also reduces the computer time required to analyze the set of data, and does not change the results.

The computer programs written over the past several years, and the experience gained in Operation HENRE and other experiments, provides us with the capability of analyzing nuclear emulsion data to obtain neutron spectra for both edge normal and isotropic exposure conditions and to adequately represent the statistical errors. 


\section{ACKNOWLEDGMENTS}

The authors acknowledge the members of the Instrumentation Division for designing and fabricating our automatic processing system, especially Vincent Negro, Sidney Watnick and Herbert Leverett.

Special thanks are also extended to Arthur Lazanoff, formerly of this laboratory and now with Control Data corporation, who devised the procedure and wrote the computer code for packing our coordinate data, as well as our Drexel students who did much of the tedious scanning. 


\section{REFERENCES}

1. Sanna, R., O'Brien, K., Alberg, M., Rothenberg, S. and McLaughlin, J.

Nuclear Emulsion Spectrometry at Low and Intermediate Neutron Energies

USAEC Report HASL-162, July (1964)

2. Anderson, M. E.

Neutron Energy Spectra of ${ }^{239} \mathrm{Pu}-\mathrm{Be},{ }^{238} \mathrm{Pu}-\mathrm{F}$ and ${ }^{238} \mathrm{Pu}-18 \mathrm{O}$ $(\alpha, n)$ Sources

USAEC Report MLM-1422, February (1967)

3. Akagi, H. and Lehman, R.

Neutron Dosimetry in and Around Human Phantoms by Use of Nuclear Track Emulsion

Health Physics, 9, 207 (1963)

4. Lehman, R. L. and Brisbane, R. W.

Random-Drift Sampling - A Study by Computer simulation

Nucl. Instr. and Meth., 64, 269 (1968)

5. Richards, H. T.

A Photographic Plate Spectrum of the Neutrons from the Disintegration of Lithium by Deuterons

Physical Review, 59, 796 (1941)

6. Lehman, R. L. and Wayland, J. R., Jr.

Geometry Correction Factors for Proton Recoil Track Samples Taken from Nuclear Emulsions

USAEC Report UCRL-11296, February (1964)

7. Bradner, H., Smith, F. M., Barkas, W. H. and Bishop, A. S. Range-Energy Relation for Protons in Nuclear Emulsion USAEC Report UCRL-443, AECU-589 (1949) 
8. Bogaardt, $N$. and Vigneron, $L$.

Calculation, Between 0.1 and $8 \mathrm{MeV}$, of the Range-Energy

Relation, as a Function of the Chemical Composition

of a Photographic Emulsion. Corresponding Calculation

for Deuterons, Tritons and Alpha Particles. Comparison

with the Experimental Measurements for the case of

Ilford C-2 Emulsion

Le Journal de Physique et la Radium, I1, 652 (1950)

9. Allred, J. C. and Armstrong, A. H.

Laboratory Handbook of Nuclear Microscopy

USAEC Report LA-1510, Appendix C, February (1953)

10. Goldberg, M. D., May, V. M. and Stehn, J. R.

Angular Distributions in Neutron-Induced Reactions,

Volume $1, Z=1$ to 22

USAEC Report BNL-400, 18th Edition (1962)

I1. Gammel, J. L.

Fast Neutron Physics, Part II, Section v.t.

Marion, J. B. and Fowler, J. L. (Editors)

Interscience Publishers, Ltd., London (1960)

12. Studies in Penetration of Charged Particles in Matter

Nuclear Series Report No. 39

Committee on Nuclear Science, National Academy of Sciences, Publication 1133 (1964)

13. Alsmiller, R. G., Jr., Leimdorfer, M. and Barish, J. Analytical Representation of Nonelastic Cross Sections and Particle Emission Spectra from Nucleon-Nucleus Collision in the Energy Range 25 to $400 \mathrm{MeV}$

USAEC Report ORNL-4046, April (1967)

14. Davis, F. J.

Neutron Dose Determination with Threshold Detectors

Selected Topics in Radiation Dosimetry, Proceedings of the Symposium on Selected Topics in Radiation Dosimetry, IAEA, Vienna (1960)

15. Measurement of Absorbed Dose of Neutron, and Mixtures of Neutrons and Gamma Rays

Handbook 75, National Bureau of Standards (1961) 
16. Irving, D. C., Alsmiller, R. G., Jr. and Moran, H. S. Tissue Current-to-Dose Conversion Factors for Neutrons with Energies from 0.5 to $60 \mathrm{MeV}$

USAEC Report ORNL-4032, August (1967)

17. Auxier, J. A.

Health Physics Division Annual Progress Report

USAEC Report ORNL-4168, 223-225 (1967)

18. Ritts, J. J., Solomito, E. and Stevens, P. N.

Calculations of Neutron Fluence-to-Kerma Factors for the

Human Body

USAEC Report ORNL-TM-2079, January (1968)

19. Gold, R.

An Iterative Unfolding Method for Response Matrices

USAEC Report ANL-6984, December (1964)

20. Evans, R. D.

The Atomic Nucleus

McGraw-Hill, New York (1955)

21. Hastings, C., Jr.

Approximations for Digital Computers

Princeton University Press, Princeton, N. J. (1955)

22. Straker, E. A.

Time-Dependent Neutron and Secondary Gamma-Ray Transport in an Air-Over Ground Geometry, Vol. II, Tabulated Data USAEC Report ORNL-4289, September (1968)

23. Alsmiller, R. G., Jr., and Barish, J.

Analytic Representation of Nucleon and Pion-Emission Spectra from Nucleon-Nucleous Collisions in the Energy Range 750-2000 MeV

USAEC Report ORNL-TM-2277, July (1968)

24. O'Brien, $\mathrm{K}$.

A Solution to the Transverse Shielding Problem for HighEnergy (>0.8 GeV) Electron and Proton Accelerators Paper presented at Second International Conference on Accelerator Dosimetry and Experience Stanford Linear Accelerator Center, November (1969) 


\section{APPENDIX 1}

\section{AN AUTOMATIC ·PROCESSING* SYSTEM}

An automatic processing system for thick nuclear track emulsions was designed and fabricated by the HASL Instrumentation Division. It is capable of processing up to 40,2 " $\times 3$ " emulsions at one time using the isothermal processing method( 1,3 ). We will first describe the components and operation of the system and then a typical processing cycle.

\section{Components and Operation}

a. The Control Panel - The process controller enables one to select the times for each processing step and to start or stop the processing cycle at any point. Four diode plug boards allow the operator to select the time for each processing step over the range of 1 minute to 9999 minutes. Step No. 1 is the developer; No. 2, the stop bath; Nos. 3 and 4 , the fix; Nos. 5 and 6 , the $50 \%$ and $25 \%$ fix baths; Nos. 7 and 8 , the $6 \%$ and $0 \%$ fix baths; Nos. 9 - 14, wash; No. 15, 50\% alcohol; Nos. 16 and $17,75 \%$ and $100 \%$ alcohol. Function and elapsed time lights indicate the step the process is in and how much time has elapsed since the start of that step. Along the bottom are the control switches. Switches and buttons permit the operator to program the system, place it into normal operation, reset time, and to advance to whatever step is desired before the program is started. The program start button is used to start the system and the program interrupt switch is used to stop the program upon completion of the step it is performing.

b. Processing Tank - The processing tank is a $2 \frac{7}{6}$ gallon stainless steel tank immersed in an ethylene glycol bath to keep the temperature of the chemicals at $5 \pm 7^{\circ} \mathrm{C}$ during processing. The ethylene glycol is cooled and circulated by a Dunkan Bush compressor. It is equipped with two stirrers to agitate the solutions and a recording thermometer to check on the temperature. Below the tank in the ethylene glycol bath a pre-cooler is located which lowers the temperature of the chemicals from ambient to $5^{\circ} \mathrm{C}$ as they are pumped into the processing tank. The developing racks are made of plastic and have $\frac{1}{4} "$ mesh nylon screen shelves to hold the emulsions. 
c. Storage Tanks - Six, five gallon plastic storage tanks hold the necessary chemicals for a development and a still with a 25 gallon storage tank supplies the distilled water. The flow of chemicals is through stainless steel tubing and is controlled by solenoid valves with nylon bodies to resist corrosion.

To develop a batch of emulsion the following procedure is followed. Choosing one of the wash steps (No. 9-14) and setting it for a long time $(\sim 1,000 \mathrm{~min})$ the tank is filled with distilled water and the compressor is turned on. It takes about one hour to cool the system to $5^{\circ} \mathrm{C}$. When the water has reached $5^{\circ} \mathrm{C}$ and is holding this temperature (the temperature can be adjusted by a control on the compressor) the emulsions are unwrapped and placed on processing racks. At this time the thickness of each emulsion is measured with a micrometer and their lengths and widths traced on paper for later measurement with a ruler.

The wash step time is now set for the elapsed time plus forty five minutes and the program interrupt switch is placed in the on position. The emulsions are placed in the water and this step is used as the presoak. About 5 minutes before the end of the presoak the amidol is added to the developer in tank No. 1 . On completion of the presoak the controller is reset to function No. $I$ and the correct time for each processing step is selected. The program interrupt switch is turned off and the processor is started. The processor will now automatically develop, stop, fix, wash, and soak the emulsions in alcohol up to $100 \%$ concentration.

At the end of the last step the emulsions are removed from the tank and allowed to dry on the processing racks for at least 24 hours. They are then "squeegeed" onto glass slides and are ready to scan. The operator need only be present to start the presoak and development steps and to remove the processing racks after the alcohol baths. For the rest of the processing no attendance is required. If the tank fails to drain or fill properly at the beginning and end of each step in alarm is sounded and the operator, if he cannot fix the trouble, can remove the emulsions from the processing tank and manually complete the processing in a refrigerator. 
TABLE 1

PROCESSING TIMES FOR 600 MICRON THICK PELLICLES

\begin{tabular}{|c|c|c|c|c|}
\hline Step & $\begin{array}{c}\text { Normal } \\
\mathrm{G}-5 \\
\end{array}$ & $\begin{array}{c}\text { Normal } \\
\mathrm{K}-2 \\
\end{array}$ & $\begin{array}{c}4 \mathrm{X} \text { Gel } \\
\mathrm{G}-5 \\
\end{array}$ & $\begin{array}{c}4 \mathrm{X} \text { Gel } \\
\mathrm{K}-2\end{array}$ \\
\hline Presoak & $45 \mathrm{~min}$ & $45 \mathrm{~min}$ & $45 \min$ & $45 \mathrm{~min}$ \\
\hline Developer* & $1.5 \mathrm{hrs}$ & $4.5 \mathrm{hrs}$ & $4.5 \mathrm{hrs}$ & $13.5 \mathrm{hrs}$ \\
\hline Stop & $45 \mathrm{~min}$ & $45 \mathrm{~min}$ & $45 \mathrm{~min}$ & 45 min \\
\hline Fix** & 24 hrs & 24 hrs & 24 hrs & 24 hrs \\
\hline $50 \%$ Fix & $30 \mathrm{~min}$ & $30 \mathrm{~min}$ & $30 \mathrm{~min}$ & $30 \mathrm{~min}$ \\
\hline $25 \%$ Fix & $30 \mathrm{~min}$ & $30 \mathrm{~min}$ & $30 \mathrm{~min}$ & $30 \mathrm{~min}$ \\
\hline $6 \%$ Fix & $45 \mathrm{~min}$ & $45 \mathrm{~min}$ & $45 \mathrm{~min}$ & $45 \mathrm{~min}$ \\
\hline $0 \%$ Fix & $45 \mathrm{~min}$ & $45 \mathrm{~min}$ & $45 \mathrm{~min}$ & $45 \mathrm{~min}$ \\
\hline Washt & $1.5 \mathrm{hrs}$ & $1.5 \mathrm{hrs}$ & $1.5 \mathrm{hrs}$ & $1.5 \mathrm{hrs}$ \\
\hline $50 \%$ ETOH & $1.0 \mathrm{hr}$ & $1.0 \mathrm{hr}$ & $1.0 \mathrm{hr}$ & $1.0 \mathrm{hr}$ \\
\hline 75\% ETOH & $1.0 \mathrm{hr}$ & $1.0 \mathrm{hr}$ & I. $0 \mathrm{hr}$ & $1.0 \mathrm{hr}$ \\
\hline 100\% ETOH & $1.0 \mathrm{hr}$ & $1.0 \mathrm{hr}$ & $1.0 \mathrm{hr}$ & $1.0 \mathrm{hr}$ \\
\hline Dry & 24 hrs & $24 \mathrm{hrs}$ & $24 \mathrm{hrs}$ & 24 hrs \\
\hline
\end{tabular}

*As Amidol oxidizes very rapidly the developing solution is changed every 1.5 hrs and replaced with freshly mixed developer.

**When developing a large number of pellicles (more than 12 , $1 " \times 3 " x 600)$ at one time in our 1 gallon tank, the fix solution is replenished or changed after several hours to avoid saturation and incomplete fixing, which leaves the pellicles fogged.

†Wash water is changed frequently, approximately every 15 minutes.

¥The alcohol solutions are composed of:

$50 \%$ ETOH - 30\% ETOH, 20\% glycerin and $50 \% \mathrm{H}_{\mathrm{B}} \mathrm{O}$

$75 \% \mathrm{ETOH}-55 \% \mathrm{ETOH}, 20 \%$ glycerin and $25 \% \mathrm{H}_{2} \mathrm{O}$

$100 \%$ ETOH - 80\% ETOH, $20 \%$ glycerin and $0 \% \mathrm{H}_{2} \mathrm{O}$ 


\section{TABLE 2}

EMULSION DETECTION EFFICIENCIES

\begin{tabular}{cc}
\hline$E_{\mathrm{n}}(\mathrm{MeV})$ & $\begin{array}{c}\text { Detection } \\
\text { Efficiency }(\%)\end{array}$ \\
\hline 0.1 & 24.0 \\
0.5 & 13.0 \\
1.0 & 9.0 \\
5.0 & 3.5 \\
10.0 & 2.0 \\
25.0 & 0.7 \\
\hline
\end{tabular}


TABLE 3

REACTION RATE PER CENTIMETER OF EMULSION FOR EDGE NORMAL INCIDENT MONOENERGETIC NEUTRONS

\begin{tabular}{lrr}
\hline $\begin{array}{c}\text { Distance } \\
\text { into } \\
\text { Emulsion } \\
(\mathrm{cm})\end{array}$ & $\begin{array}{c}\text { Number of Interactions } \\
\text { per } \mathrm{cm}^{*}\end{array}$ \\
\hline & $\mathrm{E}_{\mathrm{n}}=0.1 \mathrm{MeV}$ & $\mathrm{E}_{\mathrm{n}}=0.7 \mathrm{MeV}$ \\
0.25 & 1110 & 1010 \\
0.75 & 1148 & 1079 \\
1.25 & 1068 & 1055 \\
1.75 & 1081 & 1027 \\
2.25 & 1108 & 1059 \\
2.75 & 1014 & 977 \\
3.25 & 1007 & 1003 \\
3.75 & 983 & 979 \\
4.25 & 943 & 1030 \\
4.75 & 954 & 953 \\
5.25 & 962 & 1027 \\
5.75 & 947 & 957 \\
6.25 & 934 & 943 \\
6.75 & 889 & 925 \\
7.25 & 852 & 976 \\
\hline
\end{tabular}

*Average number of interactions per $\mathrm{cm}$ is $1000 \pm 33$. 


\section{TABLE 4}

COEFFICIENTS FOR

RANGE ENERGY RELATION

$$
\left(\mathrm{E}=\mathrm{a} \cdot \mathrm{R}^{\mathrm{b}}\right)
$$

\begin{tabular}{llll}
\hline \multicolumn{1}{c}{$\begin{array}{c}\mathrm{E} \\
\mathrm{MeV}\end{array}$} & \multicolumn{1}{c}{$\begin{array}{c}\mathrm{R} \\
\text { Microns }\end{array}$} & \multicolumn{1}{c}{$\mathrm{a}$} & \multicolumn{1}{c}{$\mathrm{b}$} \\
\hline $0<\mathrm{E} \leq 0.3$ & & & \\
$0.3<\mathrm{E} \leq 0.7$ & $0<\mathrm{R} \leq 2.9$ & 0.120967746 & 0.853056788 \\
$0.7<\mathrm{E} \leq 1.4$ & $2.9<\mathrm{R} \leq 8.7$ & 0.131572008 & 0.774134040 \\
$1.4<\mathrm{E} \leq 2.6$ & $8.7<\mathrm{R} \leq 23.5$ & 0.154785699 & 0.697556615 \\
$2.6<\mathrm{E} \leq 5.0$ & $23.5<\mathrm{R} \leq 60.0$ & 0.174039960 & 0.660418928 \\
$5.0<\mathrm{E} \leq 10.0$ & $60<\mathrm{R} \leq 173.0$ & 0.207453668 & 0.617524981 \\
$10.0<\mathrm{E} \leq 15.0$ & $173<\mathrm{R} \leq 564.1$ & 0.243484855 & 0.586443252 \\
$15.0<\mathrm{E}$ & $564.1<\mathrm{R} \leq 1136$ & 0.254917681 & 0.579205275 \\
& $1136<\mathrm{R}$ & 0.264874101 & 0.573759377 \\
\hline
\end{tabular}


TABLE 5

AVERAGE COSINE $\theta$ FOR PYRAMID OF HALF ANGLES A AND B

\begin{tabular}{rcccccccc}
\hline $\mathrm{A} / \mathrm{B}$ & 5 & 10 & 15 & 20 & 25 & 30 & 35 \\
\hline & & & & & & & \\
5 & .9974 & .9935 & .9865 & .9760 & .9609 & .9396 & .9090 \\
10 & .9935 & $.9895 *$ & .9826 & .9721 & .9570 & .9356 & .9050 \\
15 & .9865 & .9826 & .9756 & .9650 & .9498 & .9283 & .8974 \\
20 & .9760 & .9721 & .9650 & $.9543 * *$ & .9390 & .9171 & .8857 \\
25 & .9609 & .9570 & .9498 & .9390 & .9233 & .9010 & .8689 \\
30 & .9396 & .9356 & .9283 & .9171 & .9010 & .8780 & .8446 \\
35 & .9090 & .9050 & .8974 & .8857 & .8689 & .8446 & .8089 \\
& & & & & & & & \\
\hline
\end{tabular}

*Our value for $A=B=10^{\circ}$ of 0.9895 agrees with the Reference 8 value of 0.9893 .

**Our value for $A=B=20^{\circ}$ of 0.9543 agrees with the Reference 8 value of 0.9561 . 
TABLE 6

PROTONS UNDERGOING NON-ELASTIC COLLISIONS

\begin{tabular}{rccc}
\hline & $\begin{array}{c}\% \\
\text { (MeV) }\end{array}$ & $\begin{array}{c}\% \\
\text { Calculated }\end{array}$ & $\begin{array}{c}\text { Difference } \\
\text { Fit Calc. }\end{array}$ \\
\hline 1 & 0.01 & 0.05 & 0.04 \\
5 & 0.09 & 0.25 & 0.16 \\
10 & 0.28 & 0.51 & 0.23 \\
25 & 1.10 & 1.60 & 0.50 \\
50 & 3.60 & 3.80 & 0.20 \\
100 & 10.00 & 10.00 & $<0.01$ \\
150 & 18.00 & 18.00 & $<0.01$ \\
200 & 26.00 & 26.00 & $<0.01$ \\
300 & 42.00 & 42.00 & $<0.01$ \\
400 & 57.00 & 57.00 & $<0.01$ \\
\hline
\end{tabular}


TABLE 7

RATIO OF MONTE CARLO CORRECTION FACTORS TO RICHARDS' CORRECTION FACTORS FOR $20^{\circ}$ ACCEPTANCE HALF ANGLE

\begin{tabular}{|c|c|c|c|c|}
\hline$E$ & $\mathrm{Pu}-\mathrm{Be}^{(4)}$ & $14 \mathrm{MeV}^{(23)}$ & $\mathbf{E}$ & $\begin{array}{l}2 \mathrm{GeV} \\
\text { Protons on } \\
\text { Aluminum } 2\end{array}$ \\
\hline .75 & 1.000 & 1.000 & 0.5 & 0.999 \\
\hline I. 25 & 0.999 & 1.000 & 1.5 & 0.998 \\
\hline 1.75 & 0.997 & 1.000 & 2.5 & 0.994 \\
\hline 2.25 & 0.993 & 0.999 & 3.5 & 0.988 \\
\hline 2.75 & 0.990 & 0.995 & 4.5 & 0.889 \\
\hline 3.25 & 0.991 & 0.996 & 5.5 & 0.975 \\
\hline 3.75 & 0.957 & 0.999 & 6.5 & 0.970 \\
\hline 4.25 & 0.987 & 0.999 & 7.5 & 0.963 \\
\hline 4.75 & 0.982 & 0.990 & 8.5 & 0.950 \\
\hline 5.25 & 0.973 & 0.991 & 9.5 & 0.930 \\
\hline 5.75 & 0.973 & 0.979 & 10.5 & 0.934 \\
\hline 6.25 & 0.982 & 0.977 & 11.5 & 0.944 \\
\hline 6.75 & 0.977 & 0.990 & 13.0 & 0.892 \\
\hline 7.25 & 0.966 & 0.998 & 15.0 & 0.855 \\
\hline 7.75 & 0.959 & 0.998 & 17.0 & 0.798 \\
\hline 8.25 & 0.950 & 0.981 & 19.0 & 0.744 \\
\hline 8.75 & 0.952 & 0.976 & 21.0 & 0.678 \\
\hline 9.25 & 0.940 & 0.999 & 23.0 & 0.626 \\
\hline 9.75 & 0.934 & 0.978 & 25.0 & 0.636 \\
\hline 10.25 & 0.910 & 0.973 & 27.5 & 0.611 \\
\hline 10.75 & & 1.021 & 32.5 & 0.612 \\
\hline 11.25 & & 1.032 & 37.5 & 0.605 \\
\hline 11.75 & & 1.000 & 42.5 & 0.564 \\
\hline 12.25 & & 0.968 & 47.5 & 0.625 \\
\hline 12.75 & & 0.968 & 52.5 & 0.673 \\
\hline 13.25 & & 0.954 & 57.5 & 0.690 \\
\hline 13.75 & & 0.912 & 65.0 & 0.729 \\
\hline 14.25 & & 0.863 & 75.0 & 0.833 \\
\hline \multirow[t]{3}{*}{14.75} & & 0.778 & 85.0 & 0.988 \\
\hline & & & 95.0 & 0.995 \\
\hline & & & 105.0 & 0.990 \\
\hline
\end{tabular}


TABLE 8

SPECIFIC DOSE FOR $23{ }^{\circ} \mathrm{Pu}-\mathrm{Be}$ NEUTRONS

\begin{tabular}{|c|c|c|}
\hline & \multicolumn{2}{|c|}{$\times 10^{-\theta} \mathrm{rads} /\left(\mathrm{n} / \mathrm{cm}^{2}\right)$} \\
\hline & lst Collision & Maximum \\
\hline $\begin{array}{l}\text { Monte Carlo simulation of } \\
\text { Anderson's stilbene measurement, } \\
\text { edge normal data }\end{array}$ & 3.821 & 5.292 \\
\hline $\begin{array}{l}\text { Spectrum obtained from analyses } \\
\text { of Monte Carlo coordinate data }\end{array}$ & $4.0 \pm 0.4$ & $5.6 \pm 0.5$ \\
\hline $\begin{array}{l}\text { HASL } 10 \mathrm{Ci} 230 \mathrm{Pu}-\mathrm{Be} \text { emulsion } \\
\text { measurement }\end{array}$ & $4.0 \pm 0.5$ & $5.6 \pm 0.7$ \\
\hline $\begin{array}{l}\text { HERMES results for Monte carlo } \\
\text { simulation of Anderson's } \\
\text { Stilbene measurement }\end{array}$ & $3.91 \pm 0.02$ & $5.43 \pm 0.02$ \\
\hline
\end{tabular}




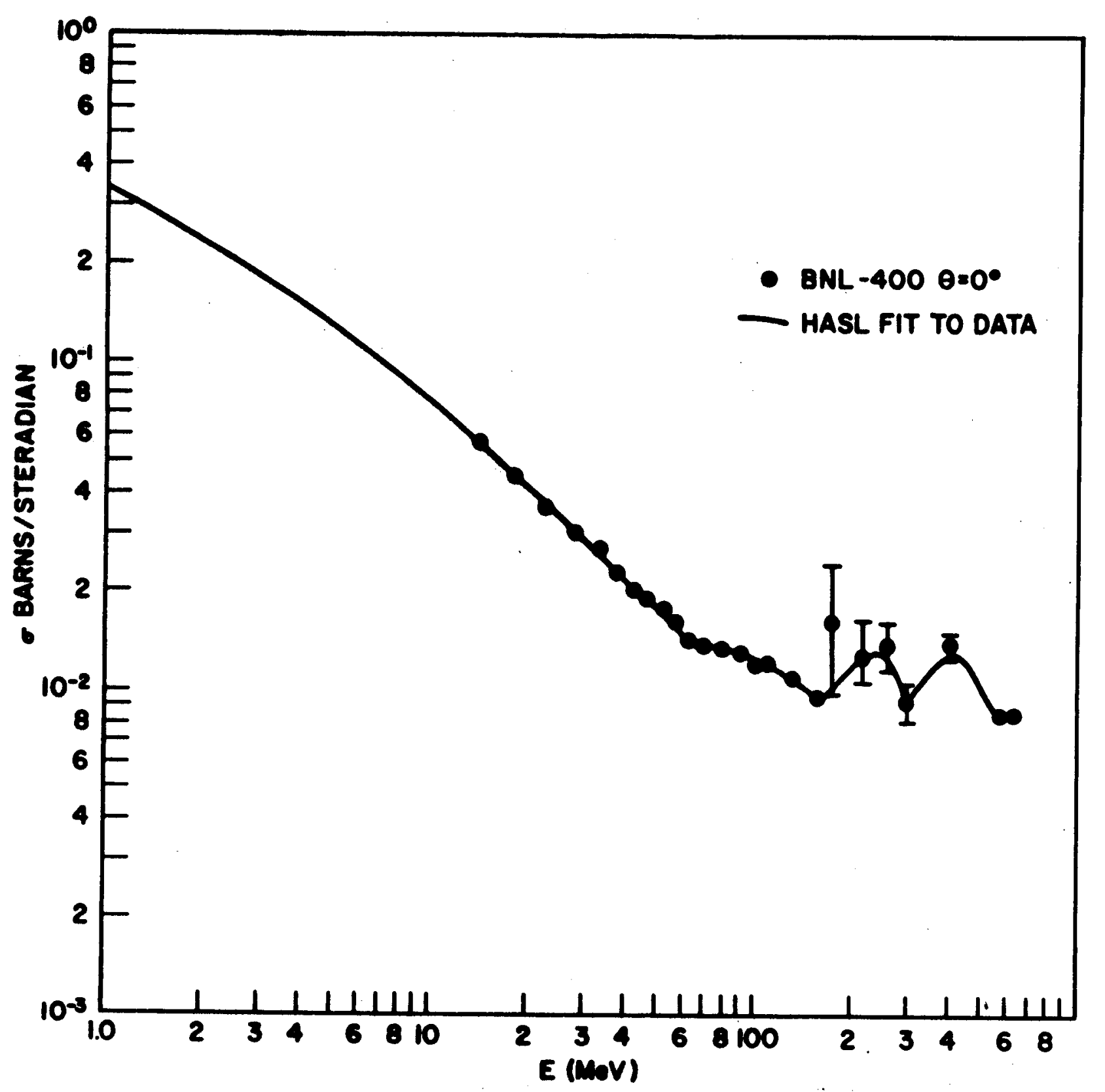

Figure I. The differential np scattering cross section in the forward direction. 


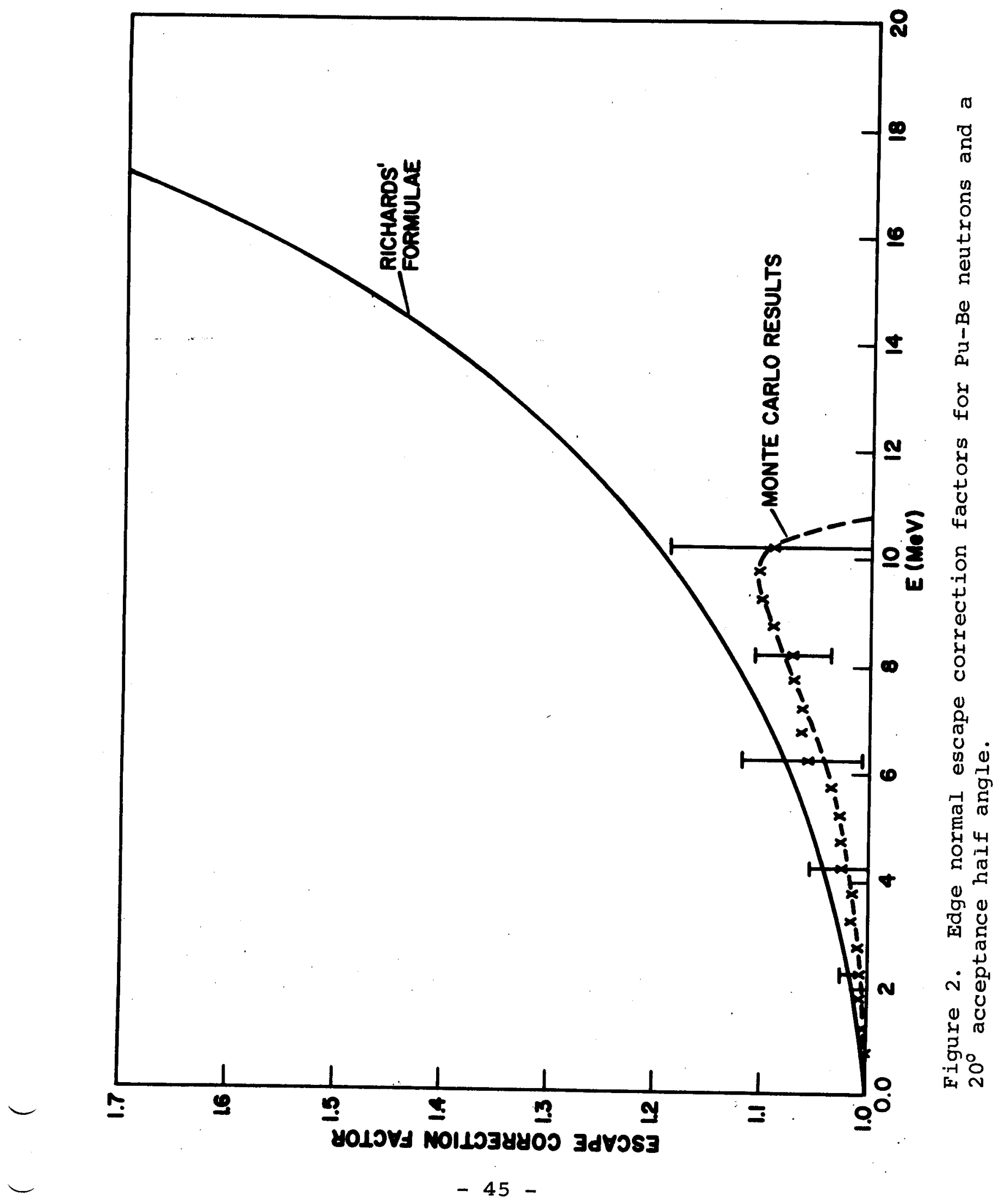




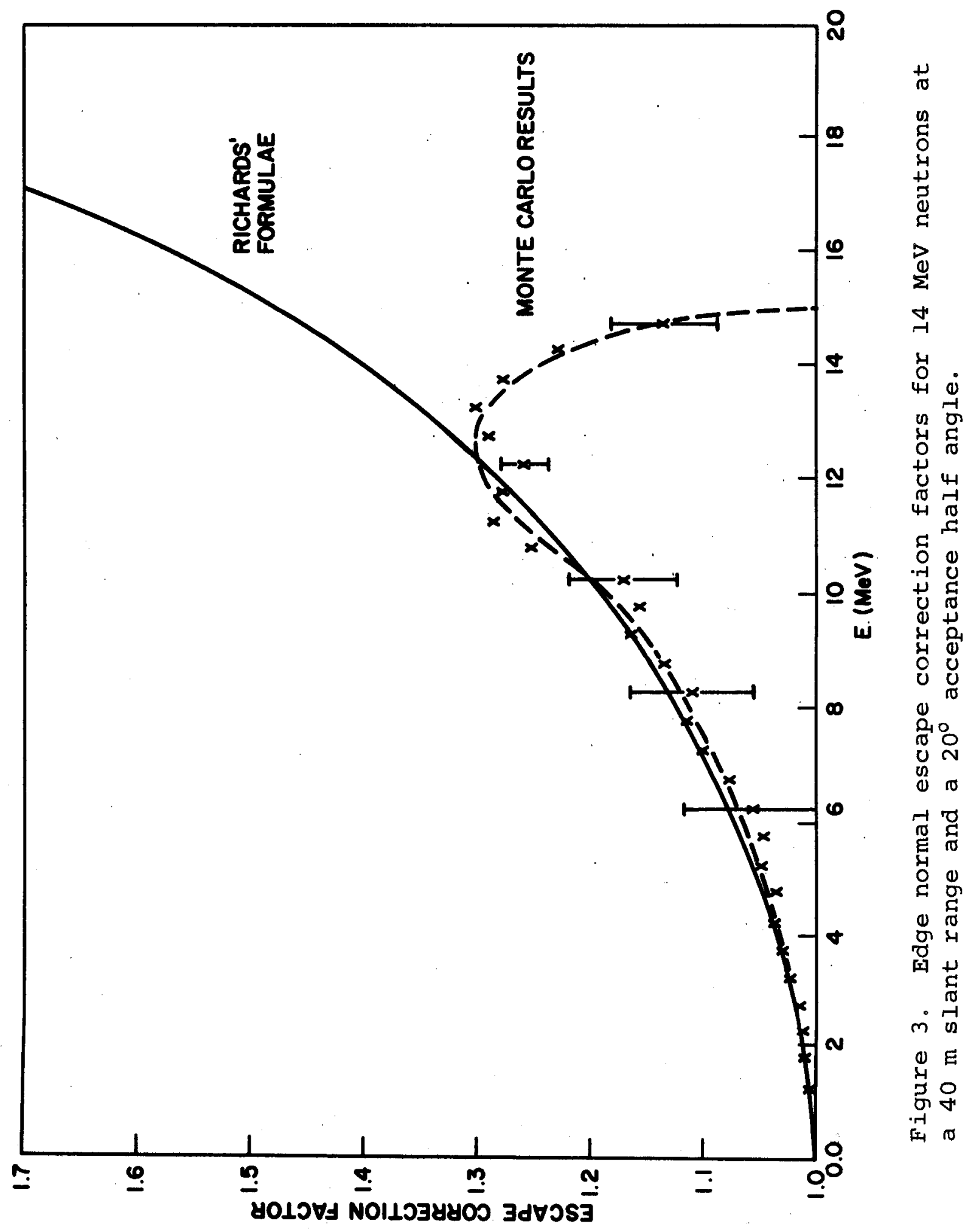




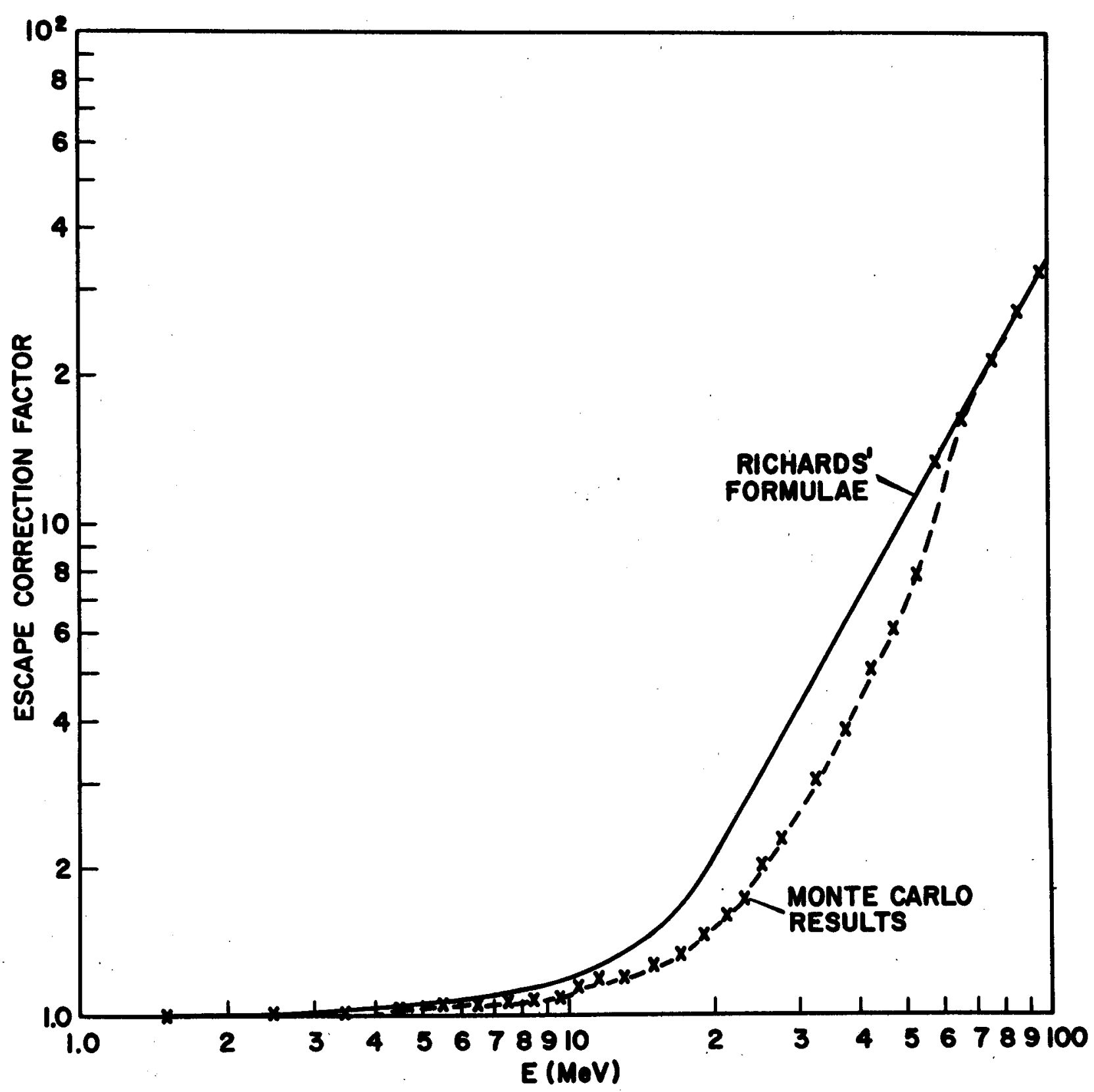

Figure 4. Edge normal escape correction factors for secondary neutrons from $2 \mathrm{GeV}$ protons on aluminum and a $20^{\circ}$ acceptance half angle. 


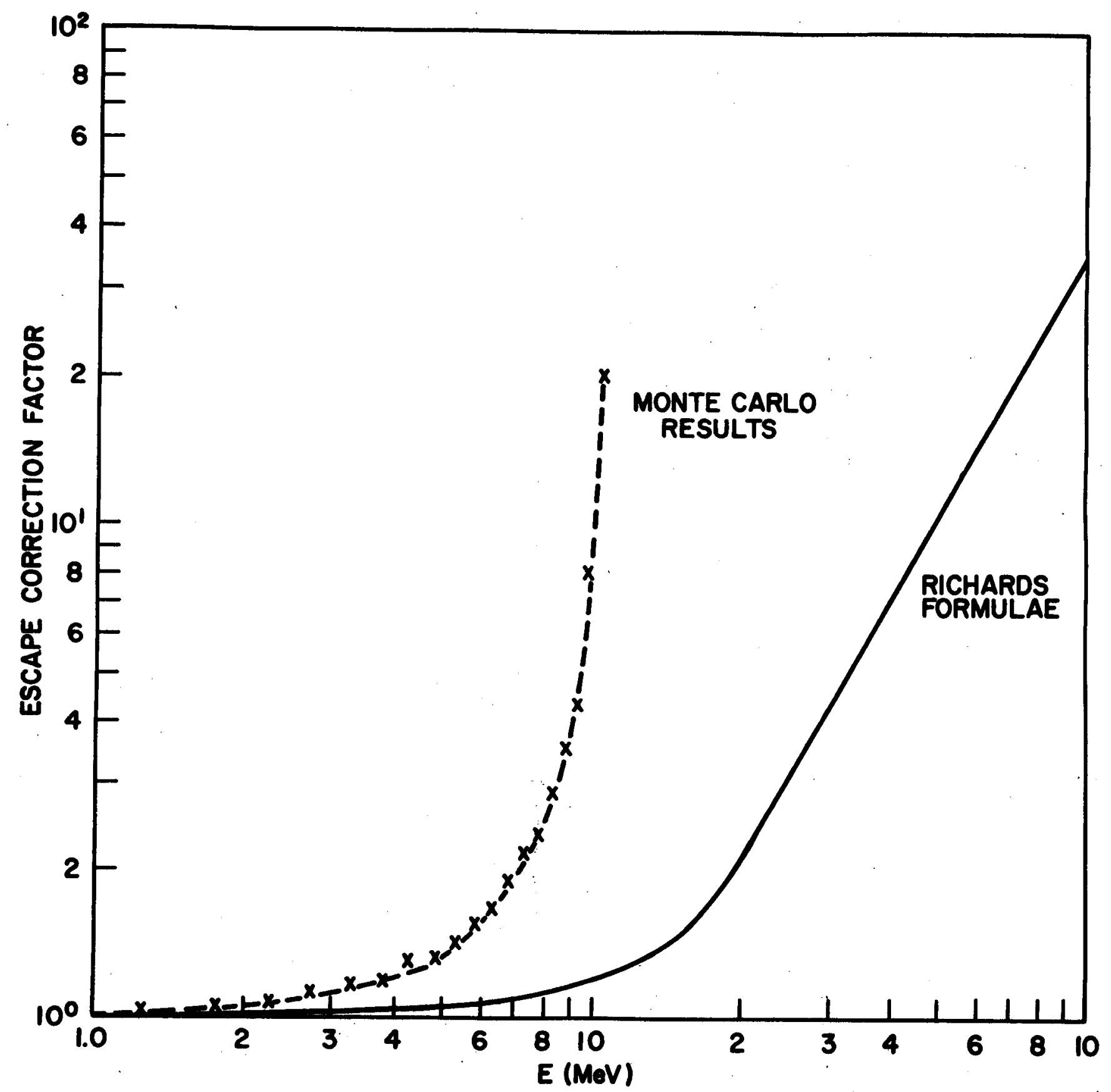

Figure 5. Face normal escape correction factors for $\mathrm{Pu}-\mathrm{Be}$ neutrons and a $20^{\circ}$ acceptance half angle. 


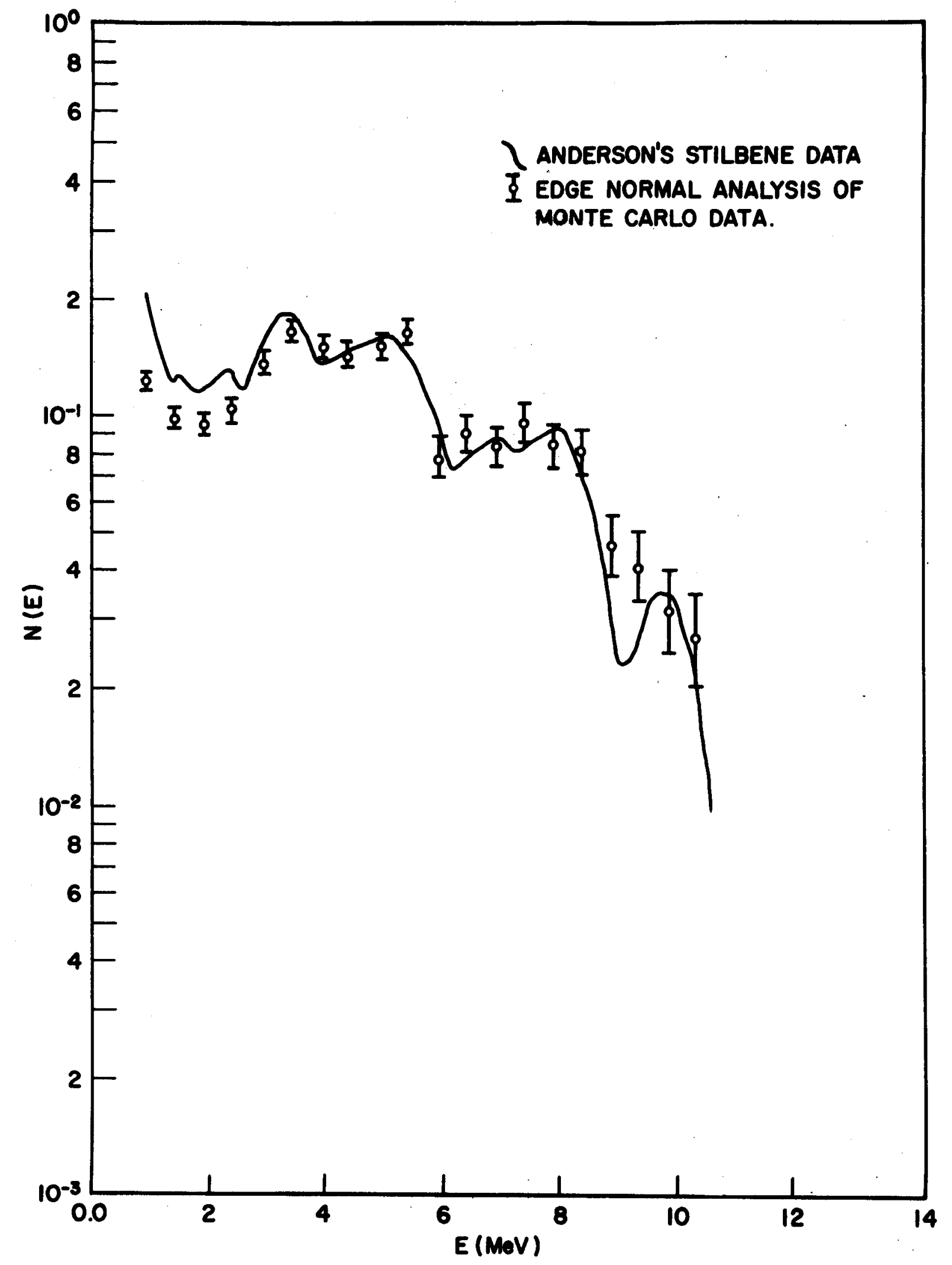

Figure 6. Neutron spectrum from Monte Carlo generated coordinate data for edge normal exposure to $\mathrm{Pu}-\mathrm{Be}$ neutrons. 


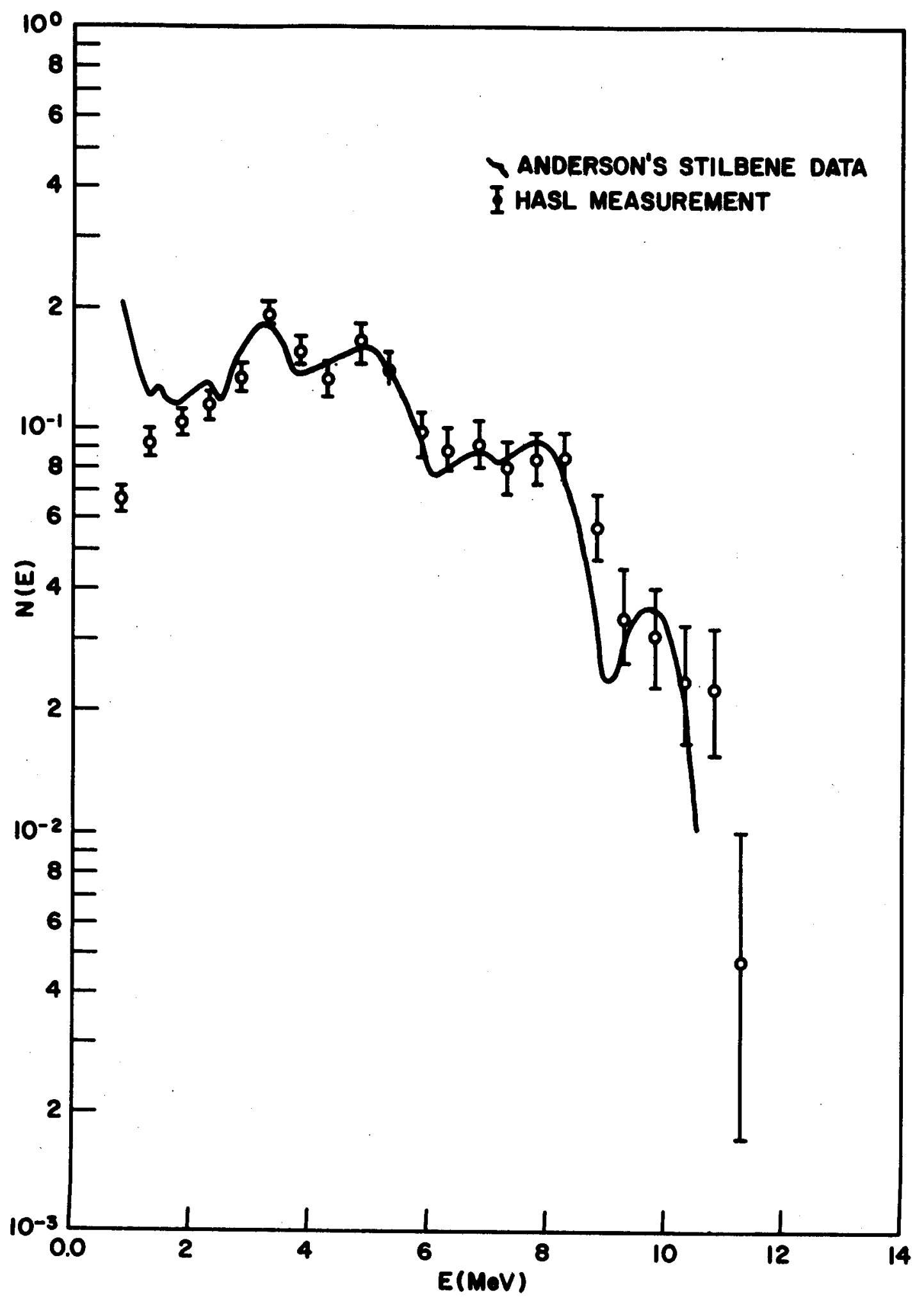

Figure 7. HASL $10 \mathrm{Ci} 239 \mathrm{Pu}-\mathrm{Be}$ neutron source spectrum measured with nuclear emulsions, edge normal exposure. 


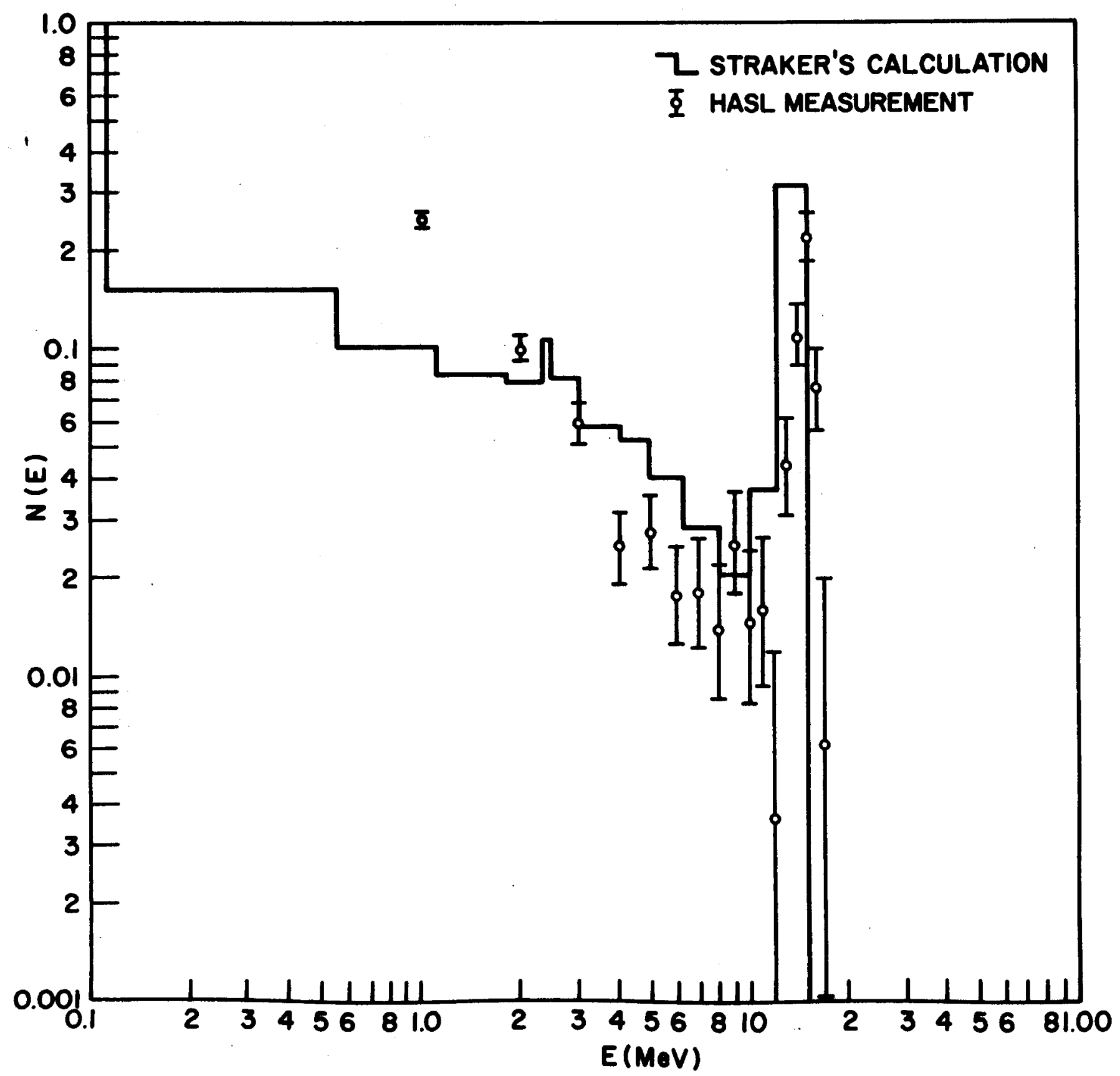

Figure 8. HASL measurement of D-T neutron spectrum at a slant range of 11 meters, edge normal exposure. 


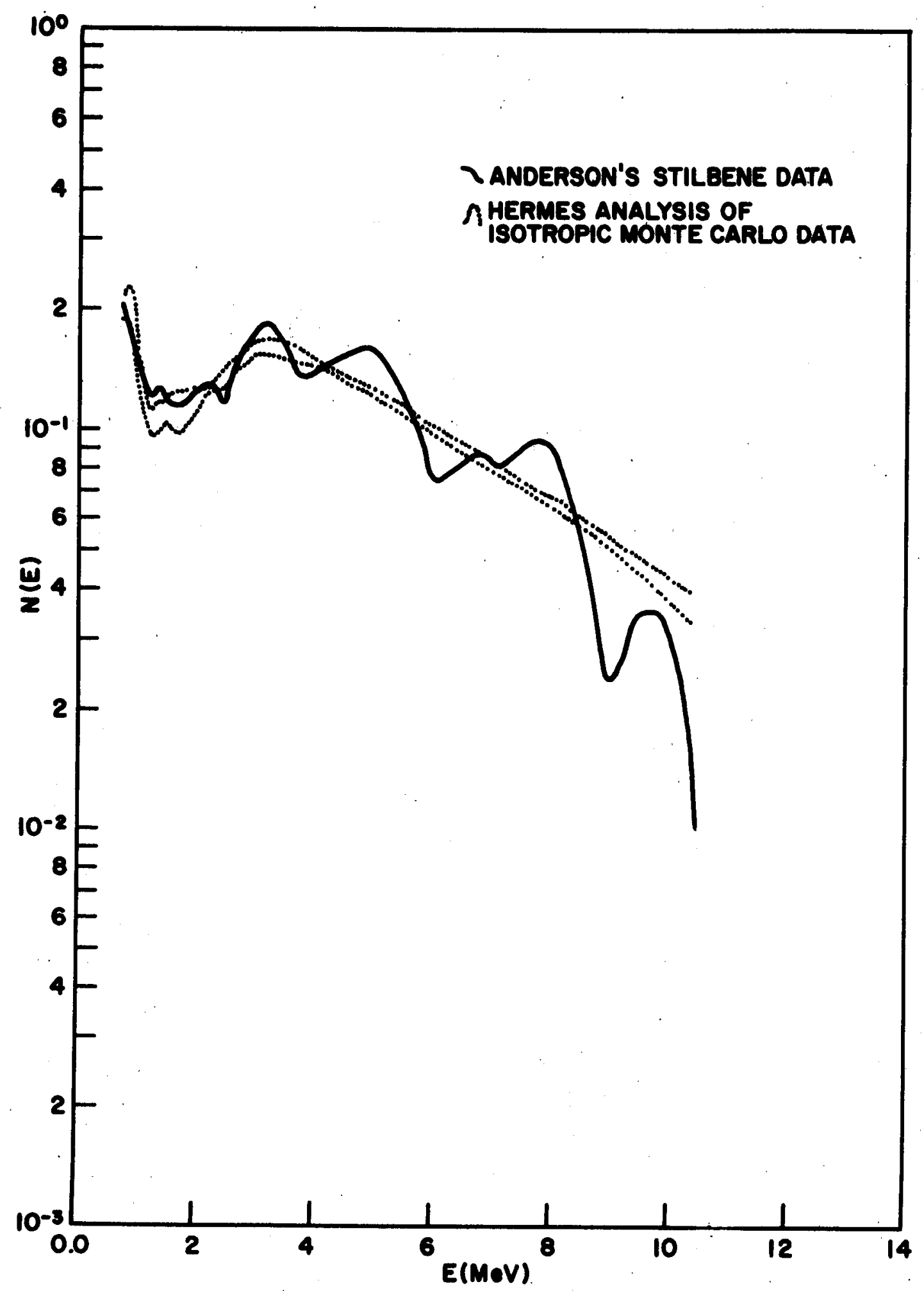

Figure 9. Neutron spectrum from Monte Carlo generated coordinate data for an isotropic exposure to $\mathrm{Pu}-\mathrm{Be}$ neutrons. 


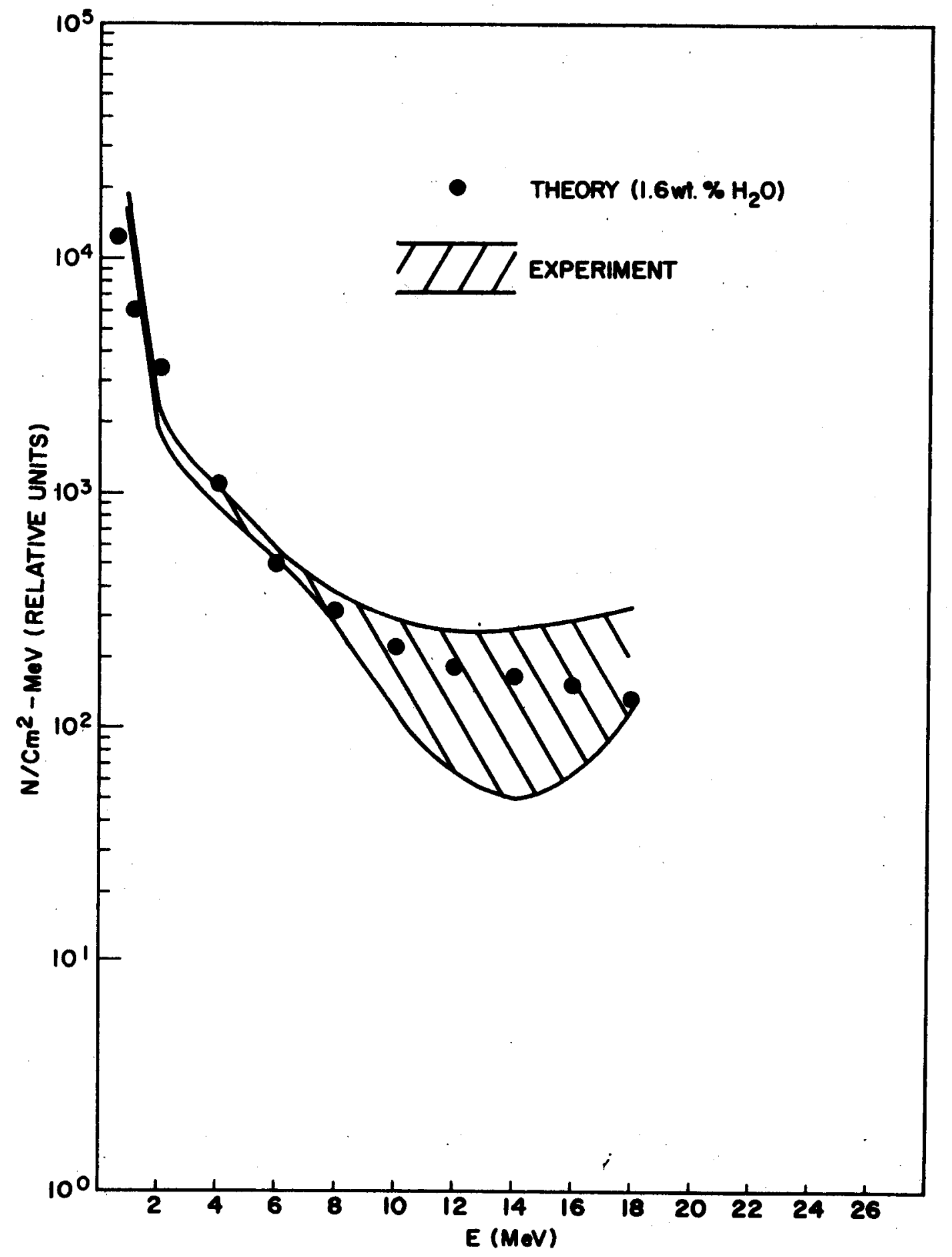

Figure 10. Comparison of nuclear track emulsion neutron spectral measurement made alongside the BNL Cosmotron with theory. 